$66 / 2016$

\title{
LA LENGUA COMO CANON Y COMO OBJETO DE CRÍTICA EN LA GRAMÁTICA NORMATIVA
}

Elena Leal Abad

Universidad de Sevilla

lealabad en us.es

Resumen

La selección de las muestras de ejemplos que se emplean en la codificación normativa del español está relacionada con las concepciones teóricas que en cada época histórica sirven de base para acometer la reflexión gramatical. La autoridad sobre el uso ha correspondido tradicionalmente en la preceptiva académica a las fuentes literarias, que se han empleado fundamentalmente para ilustrar la pauta normativa tanto en la labor lexicográfica como en la gramatical. La incorporación de nuevas tipologías textuales en la producción académica está vinculada a un cambio en la concepción teórica en la que una lengua ya no es concebida como un bloque monolítico y homogéneo, sino donde la variación lingüística se constituye en rasgo inherente a su misma condición histórica.

Leal Abad, Elena. 2016.

La lengua de los medios como canon y como objeto de crítica.

Círculo de Lingüistica Aplicada a la Comunicación 66, 148-194.

http://www.ucm.es/info/circulo/no66/leal.pdf

http://revistas.ucm.es/index.php/CLAC

http://dx.doi.org/10.5209/CLAC.52771

(C) 2016 Elena Leal Abad

Círculo de Lingüística Aplicada a la Comunicación (clac)

Universidad Complutense de Madrid. ISSN 1576-4737. http://www.ucm.es/info/circulo 
De ahí que no resulte extraño que en la nómina de textos sea cada vez más frecuente encontrar un amplio corpus conformado por publicaciones periódicas. Esta incorporación de muestras periodísticas en la reciente producción académica, materializada en el Diccionario panhispánico de dudas (2005) y en la Nueva gramática de la lengua española (2009), viene a suplir en cierta medida también el silencio normativo académico ante las dudas y vacilaciones lingüísticas planteadas por los profesionales de los medios de comunicación.

Tras el rastreo histórico de la aparición de muestras periodísticas en la ejemplificación normativa académica, se tratará de establecer si se ha producido un cambio en la funcionalidad de estas citas de manera que no sean ya empleadas exclusivamente con la valoración de ejemplaridad idiomática, tal y como se utilizaban fundamentalmente las muestras extraídas de los textos literarios en la labor de codificación tradicional de la Academia, sino también como variantes incorrectas objeto de una crítica más o menos velada hacia determinados usos circunscritos mayoritariamente al discurso periodístico actual.

Palabras clave: Canon lingüístico, ejemplaridad, variación, tradición discursiva, normatividad.

\section{Abstract}

The selection of examples' samples that are used in the regulatory coding of Spanish is related to theoretical concepts which are used as a basis, in each historical period, to undertake grammatical reflection. The authority over the usage has traditionally corresponded in academia to the literary sources, which have been primarily used to illustrate the normative model both in the lexicographical and grammatical task. The introduction of new textual typologies in academic production is linked to a change in the theoretical conception in which a language is no longer conceived as a monolithic and homogeneous block, but where linguistic variation constitutes an inherent feature of the same historical condition. That is why it is not surprising that, in the list of texts, it is increasingly common to find a large corpus composed of periodicals. This incorporation of newspaper samples in recent scholarship, embodied in the Diccionario panhispánico de dudas (2005) and the Nueva gramática de la lengua Española (2009), replaces also 
to some extent the academic silence in relation to the doubts and linguistic hesitations raised by media professionals.

After the historical tracking of the appearance of journalistic samples in the regulatory academic modelling, it will be sought to establish whether there has been a change in the functionality of these quotes so that they are no longer used exclusively with the assessment of idiomatic exemplary - as the samples of literary texts were mainly used in the work of academia's traditional coding -, but also as incorrect variants subject to a more or less veiled critic towards certain uses mostly confined to the current journalistic discourse.

Key words: Normative model, grammatical canon, discursive traditions.

Índice

1. Introducción 150

2. La aparición de la lengua periodística como ejemplificación en la preceptiva académica: recorrido histórico 154

3. La ejemplificación periodística en la reciente producción gramatical de la Real Academia Española: función y valoración normativa 166

4. Normativa académica y libros de estilo: ¿Relación de convivencia y reciprocidad? 185

5. Conclusiones 187

Bibliografía 191

\section{Introducción}

El interés normativo ${ }^{1}$ hacia la lengua empleada en la prensa no puede separarse de la importancia creciente que el discurso periodístico adquiere progresivamente en la sociedad porque, al constituir la palabra la herramienta de trabajo y al estar la materia

\footnotetext{
1 Este trabajo se ha realizado en el marco del proyecto de investigación "Tradiciones discursivas, tradiciones idiomáticas y unidades de análisis del discurso en la historia del español moderno" (FFI201451826-P), financiado por el Ministerio de Economía y Competitividad.
} 
informativa directamente vinculada a la actualidad, se necesitan directrices legitimadas por la autoridad lingüística competente que den respuesta a las dudas idiomáticas derivadas no solo de la peculiar situación enunciativa del oficio de informar, que determina toda una serie de estrategias lingüísticas específicas (cita de fuentes, organización jerárquica de contenidos, estilo impersonal, precisión y condensación de contenidos...), sino también de la adaptación idiomática más adecuada ante nuevas realidades y cambios sociales (aclimatación morfológica de extranjerismos, denominación de las profesiones ejercidas por mujeres... $)^{2}$.

La estabilidad de un sistema lingüístico nunca es absoluta porque este debe servir de instrumento de comunicación a una comunidad en continuo cambio - de ahí el carácter de producto histórico de las lenguas ${ }^{3}$-, lo que origina fluctuaciones o tensiones en los usos idiomáticos. Los medios de comunicación constituyen un buen reflejo de estas vacilaciones y sirven de banco de prueba (dada su permeabilidad ante lo foráneo y su urgente necesidad de denominar nuevas realidades) para que la autoridad académica en materia lingüística establezca y finalmente certifique si el consenso implícito de los hablantes termina aceptando determinadas formaciones como prestigiosas o no. No debe olvidarse que en el imaginario colectivo se atribuye a la Academia la función normativa de discernir entre lo que son cambios arbitrarios en el idioma y aquellos que constituyen modificaciones necesarias en su estructura vinculadas al devenir histórico de la lengua.

\footnotetext{
${ }^{2}$ El estudio de la lengua de los medios de comunicación se ha acometido desde perspectivas muy variadas, constituyendo la línea de investigación mayoritaria la que aborda la configuración discursiva de los textos periodísticos derivada de la peculiar situación de enunciación ligada al oficio de informar (Charaudeau 1997 y 2003). Así, existe una amplia bibliografía que da cuenta de cómo la deuda contraída con las fuentes de información condiciona la disposición de la materia informativa y la organización del discurso (Méndez 1998, 1999a, 1999b, 2001a y 2001b) o de cómo el deseo de objetividad en la transmisión de la información origina un tipo discursivo caracterizado por un estilo con pretensiones de impersonal, funcional y conciso. Los estudios que analizan estos aspectos han adoptado tradicionalmente una perspectiva sincrónica y se han centrado más frecuentemente en el plano escrito que en el oral. No obstante, en relación a este último existen trabajos que abordan el análisis del reflejo de lo oral en lo escrito en el caso de los géneros de opinión como las columnas (Mancera 2008 y 2009) o que rastrean la impronta oral como constituyente de los informativos audiovisuales.

${ }^{3}$ Se trata de uno de los universales del lenguaje identificados por Coseriu: la historicidad. Todo sistema lingüístico natural se constituye en instrumento de comunicación de una comunidad idiomática que conlleva inherentemente la variación en diferentes parámetros y determina la convivencia de soluciones lingüísticas con diferentes valoraciones asociadas: variación diacrónica, diatópica, diastrática y diafásica.
} 
No obstante, puede decirse que hasta la más reciente producción normativa académica, materializada en el Diccionario panhispánico de dudas (2005) y la Nueva gramática de la lengua española (2009) ${ }^{4}$, las dudas lingüísticas planteadas por los profesionales de los medios de comunicación se orientaban a partir de obras que no emanaban directamente de la Academia ${ }^{5}$, aunque en ocasiones recibieran su respaldo, o incluso se disipaban utilizando como tribuna el espacio cedido por los propios medios, convertidos a menudo en difusores autocríticos de sus propias infracciones normativas ${ }^{6}$. En este sentido, los libros de norma lingüística ${ }^{7}$ y los libros de estilo de los medios de

${ }^{4}$ La referencia a estas dos obras se hará a partir de ahora empleando las siglas DPD y NGLE.

${ }^{5}$ Tal y como señala Vellón (2013: 9), los apartados dedicados a cuestiones gramaticales en los libros de estilo se limitan normalmente a resumir las principales normas gramaticales de acuerdo a la autoridad académica pero en ocasiones estas obras dan respuesta a problemas lingüísticos que no aparecen en las normativas convencionales, como ocurrió con la vacilación en la formación del plural de la palabra talibán, que osciló entre los talibanes y los talibán durante mucho tiempo en la prensa española hasta que finalmente el $D P D$ y la $N G L E$ recogieron la pauta normativa. No resulta extraño, pues, que en estas dos obras las citas que ilustran las opciones gramaticales recomendadas en la formación del plural de la palabra talibán estén extraídas de los medios de comunicación. En todos los casos las fuentes periodísticas se utilizan para ejemplificar la norma y no como contraejemplos, para lo que se recurre, a pesar de que la vacilación fue muy habitual en los periódicos españoles (Blas 2002), a la construcción introspectiva: “talibán -na. 1. 'De cierta milicia integrista musulmana'. Aunque en el dialecto del persa que se habla en Afganistán la forma talibán es plural (singular talib), esta voz se ha acomodado ya a la morfología española y se usa talibán para el singular y talibanes para el plural: «El líder talibán estaba rodeado por las fuerzas que negociaban su rendición» (Prensa [Nic.] 7.1.02); «Los talibanes impusieron la ley islámica a la población» (Universal [Ven.] 15.10.96). Se desaconseja el plural invariable *los talibán" (DPD); "Plantea alguna dificultad la formación del plural de voces que son ya plurales en su lengua de origen. [...]. No se perciben como tales en español, por lo que, integrados en nuestra lengua, pasan a formar el plural siguiendo las reglas de la morfología castellana: los confetis, muchos espaguetis, pocos raviolis, etc. [...] De forma similar, el sustantivo talibán (plural en pashtu, lengua de Afganistán) forma el plural talibanes [...]: Este paquistaní que en principio se unió a los talibanes bajo presión no comprende cómo alimentó esa espiral de violencia (Caretas 18/10/2001) (NGLE, 2009: 151).

${ }^{6}$ Así, la obra El dardo en la palabra (1997) reúne una serie de artículos que Fernando Lázaro Carreter publicó entre 1975 y 1996 en periódicos de España e Hispanoamérica y su posterior El nuevo dardo en la palabra (2003) los aparecidos en el diario El País desde 1999 hasta 2002. En estas compilaciones, centradas fundamentalmente en aspectos léxicos, se hace una crítica de usos vinculados al discurso periodístico, aunque no en exclusiva, ya que también tiene cabida en ellos el discurso publicitario, político y administrativo.

${ }^{7}$ Los libros de norma lingüística emanan a veces de las instituciones normativas, como ocurre con $\mathrm{El}$ buen uso del español (RAE y ASALE 2013). En otros casos la vinculación es más indirecta por estar la obra escrita a título personal por un académico, como es el caso de El dardo en la palabra (Lázaro Carreter 1997). Estas obras, que constituyen un claro ejemplo de la conciencia crítica de la sociedad hacia los propios usos idiomático, tratan de dar respuesta de manera divulgativa a los problemas de normatividad más recurrentes. No resulta extraño, pues, que en el propio título de muchas de ellas figure la palabra $d u d a$, que pone de manifiesto la vacilación de los hablantes ante determinados usos, como sucede con el Diccionario panhispánico de dudas (2005) o Las 500 dudas más frecuentes del español (2013) del Instituto Cervantes. Se trata de una práctica iniciada con la publicación en 1961 del 
comunicación $^{8}$ suplían en parte el silencio académico ante las dudas idiomáticas seleccionando, sintetizando y contextualizando los problemas de normatividad más frecuentes que planteaba el uso del español a nivel ortográfico, léxico y gramatical en el ejercicio de la profesión periodística.

La finalidad de este estudio es establecer cuándo, cómo y por qué la lengua de los medios de comunicación se constituye en modelo de imitación o referencia del canon lingüístico en la tradición gramatical del español, al igual que ha ocurrido habitualmente con las fuentes literarias o con los ejemplos construidos por los propios tratadistas para ilustrar las explicaciones teóricas ${ }^{9}$. Se trata, pues, de un objetivo triple que conlleva en

Diccionario de dudas y dificultades de la lengua española de Manuel Seco. En la reciente producción normativa de la Academia se hace también explícita la actitud de centrar determinadas explicaciones gramaticales a partir de la vacilación (de la "duda") de los hablantes ante determinados usos idiomáticos: "Hay ocasiones en que las incorrecciones o vacilaciones en el uso de los pronombres átonos de tercera persona no se deben a la tendencia dialectal señalada en el párrafo anterior, sino a la duda del hablante sobre el tipo de complemento - directo o indirecto - que rigen algunos verbos" (DPD "Laísmo"), "Con ciertos verbos y en ciertos contextos sintácticos, es posible que no esté claro para el hablante si el complemento verbal es directo o indirecto, lo que conduce, en ocasiones, a un uso erróneo de los pronombres átonos de tercera persona" ( $D P D$ "Loísmo). En este sentido, las recientes publicaciones vinculadas a la norma idiomática del español suelen servir de mediadores entre la RAE y el público en general al hacer más divulgativos los contenidos especializados de las obras académicas. La misma institución académica es consciente de la necesidad de dirigir sus obras también a usuarios con pocos conocimientos lingüísticos, pero que requieren aprender nociones gramaticales para entender el funcionamiento de su idioma.

${ }^{8} \mathrm{La}$ preocupación de los medios de comunicación por utilizar correctamente y de forma adecuada la propia lengua se manifiesta claramente en la existencia de los libros de estilo, en los que el periodismo prescribe y regula su propia producción discursiva: "Los libros o manuales de estilo periodístico -en ocasiones, denominados manuales de redacción- cumplen diversas funciones de gran transcendencia para el desarrollo de las rutinas informativas de los medios de comunicación. [...] Desde el punto de vista lingüístico [...] los libros de estilo son verdaderas gramáticas de uso que ofrecen respuestas inmediatas a los múltiples interrogantes que se suscitan en la práctica diaria de una actividad cuyo instrumento primordial es la lengua" (Vellón 2013: 9).

${ }^{9}$ No debe olvidarse que el carácter normativo de la gramática tradicional recogía aquellos usos que se consideraban modelos idiomáticos dignos de ser imitados por corresponderse con el uso culto en su registro formal. De esta manera, la autoridad sobre el uso ha correspondido históricamente en la preceptiva académica a los autores literarios, a los que se atribuía, incluso, la potestad de dar carta de legitimidad a los cambios lingüísticos al acogerlos en su propia producción. Por el contrario, la manifestación de estos cambios en los textos periodísticos no ha tenido históricamente la misma legitimidad, al ser considerados reflejos de modas pasajeras o de ocurrencias individuales que encontraban poca resistencia a ser acogidos en un tipo de discurso altamente permeable a las innovaciones lingüísticas dada su vinculación constante con la actualidad, marcada en múltiples ocasiones por nuevas realidades para cuya designación no siempre se contaba con directrices académicas: "Cuestión aparte es la de si está facultado para innovar quien usa la voz pública, para coadyuvar al cambio de los usos y para introducir los nuevos. El padre Feijoo reconocía esa potestad sólo a los que llamaba «poetas príncipes». Quizá no haga falta sangre azul literaria para actuar en ese frente, pero sí conviene ser consciente de que lanzar novedades al mercado idiomático es - y ahora apelo a Fray Luis- «negocio de 
primer lugar rastrear históricamente la aparición de la lengua periodística como ejemplificación en la preceptiva académica; en segundo lugar, establecer la valoración otorgada, que puede oscilar desde su consideración como modelo normativo hasta su condición de objeto de crítica por no ajustarse a la pauta académica; $y$, finalmente, analizar las posibles causas de la selección de muestras extraídas de la prensa, que pueden estar motivadas por la necesidad de dar respuesta a las dudas idiomáticas reales planteadas por los usuarios en general (y por el ámbito periodístico en particular) o ser fruto de las nuevas concepciones teóricas en la reflexión gramatical.

2. La aparición de la lengua periodística como ejemplificación en la preceptiva académica: recorrido histórico

La necesidad de la existencia de pautas normativas en materia lingüística asociadas al ejercicio profesional de informar está unida a la importancia creciente que la actividad periodística tiene en la sociedad. No es fácil responder a la pregunta de cuándo nace el periodismo en España por dos razones fundamentales. En primer lugar, porque habría que precisar qué se entiende exactamente por periodismo para poder delimitar un período concreto de la historia que sirva de punto de partida; en segundo lugar, porque no es conveniente el planteamiento de la pregunta en los términos en los que está formulada, ya que se emplea una metáfora que equipara el surgimiento de nuevos tipos de discurso con el devenir biológico del ser humano. Tal equivalencia no es real puesto que los textos no surgen ex novo, sino que se insertan en tradiciones previas que van determinando su configuración lingüística y sus estrategias discursivas de acuerdo a modelos que se toman como referencia ${ }^{10}$. Los comienzos titubeantes de este género textual suelen situarse a mediados del siglo XVII, momento en el que se estabiliza una tradición discursiva existente en los dos siglos precedentes en los que, si bien no puede todavía hablarse de textos preperiodísticos en sentido estricto, sí puede decirse que

particular juicio», y que una prudente desconfianza ante las ocurrencias propias constituye una gran virtud" (Lázaro 1997: 23).

10 Una lengua se realiza siempre imbricada en una tradición discursiva, por tanto, además de la historicidad de los sistemas lingüísticos hay otra historicidad, la de los productos discursivos que combinan en diferentes proporciones repetición y creatividad y hace que los enunciados sean reconocidos como pertenecientes a una determinada tradición discursiva (Kabatek 2001, 2005, 2007). 
empieza a conformarse un tipo de tradición de carácter informativo con un objetivo público materializado en folletos breves, conocidos en la historia de la literatura mediante nombres diversos: Relaciones, Ocasionales, Avisos... (Borreguero y Octavio de Toledo 2004, 2007, Méndez 2008). No obstante, en la línea de la historicidad de los productos discursivos, consideramos que para tener una visión más completa del proceso de conformación histórica del género informativo hay que retrotraerse a tradiciones discursivas anteriores tales como el género cronístico medieval y las crónicas de Indias.

Lo dicho anteriormente pone de manifiesto la dificultad de establecer con nitidez y precisión un límite en el que situar el origen de los textos periodísticos pero sirve de contextualización para abordar el primer objetivo de este trabajo: establecer cuándo la ejemplificación procedente de la lengua de los medios aparece en la producción normativa académica del español, al igual que ha ocurrido tradicionalmente con las fuentes literarias o con los ejemplos construidos por los propios tratadistas para ilustrar las explicaciones teóricas.

En su acepción número seis, el diccionario académico define "autoridad" como 'Texto, expresión o conjunto de expresiones de un libro o escrito, que se citan o alegan en apoyo de lo que se dice'. La autoridad sobre el uso ha correspondido tradicionalmente en la preceptiva académica a la lengua literaria desde su primera obra, el Diccionario de autoridades (1726-1739), porque en él cada palabra y cada acepción figuraban apoyadas por ejemplos de autores literarios. Puesto que en el siglo XVIII se consideraba que el gusto literario contemporáneo estaba corrompido, los ejemplos del buen uso se tomaron preferentemente de periodos anteriores, en especial de los siglos XVI y XVII. Existía, pues, una valoración negativa de la producción literaria del siglo XVIII, eclipsado por el esplendor de los dos anteriores. Sin embargo, no hay que olvidar que este siglo supone el afianzamiento de formas discursivas nuevas ensayadas en la centuria anterior (en el ámbito científico, doctrinal, técnico, etc.) y la consolidación de la prensa en España ${ }^{11}$,

\footnotetext{
${ }^{11}$ La aparición de las primeras formas de periodismo suele situarse en Europa durante el siglo XVII. A partir de 1605 se inicia una evolución lenta y dispersa de este nuevo medio de comunicación, de manera
} 
que también contaba con precedentes en la centuria anterior ${ }^{12}$. Es posible que a la poca estima hacia el gusto literario dieciochesco por parte de la Academia, se añadiera una consideración poco prestigiosa o un juicio de valor negativo desde el punto de vista de la ejemplaridad idiomática hacia estos primeros textos de carácter informativo, elaborados sin ninguna pretensión literaria y con un marcado carácter utilitario y funcional. La redacción rápida y apresurada de estos textos, junto a su carácter efímero los alejaría probablemente del ideal de modelo idiomático que debía ilustrar las voces propias del uso culto formal y, por lo tanto, podría explicar su completa ausencia de una obra como el Diccionario de autoridades.

Sin embargo, la producción lexicográfica académica más reciente sí ha tenido en cuenta para su ejemplificación el discurso periodístico. De este modo, aun siendo mayoritaria la autoridad literaria, el Diccionario histórico del español (1933-1936 y 1960-1996) incluye en la nómina de autores y obras que se citan publicaciones periódicas de revistas y periódicos, contemporáneos en su mayoría y editados fundamentalmente en España. Sirva como ejemplo el tomo I (1960), que recoge una amplia nómina ${ }^{13}$, completada por otras listas de textos recogidas específicamente en los sucesivos fascículos ${ }^{14}$. La ejemplificación extraída de estas publicaciones tiene una especial presencia en las

que "[h] asta finales del siglo XVIII no fueron comunes los periódicos diarios y hasta bien entrado el siglo XIX no empezaron a tomar el aspecto con que hoy aún los conocemos" (Guillamet 2004: 43).

${ }^{12}$ La aparición del primer periódico, la Gaceta Nueva, que se documenta en la segunda mitad del siglo XVII, concretamente en 1661.

${ }^{13}$ ABC. Diario ilustrado de información general (Madrid, 1905 y sigs.), Agua. Revista del centro de estudios, investigación y aplicaciones del agua (Noviembre-diciembre 1967), Arriba, Diario de los literatos de España (ts. 1 a 7 Madrid. 1737), Diario de Madrid, El Alcázar (Diario gráfico de la tarde. Madrid. 1946 y sigs.), El Liberal (Madrid 1879-1939), El Sol. (Diario independiente. Madrid. 19171937), El Universo (Madrid 1900-1926), Ibérica. El progreso de las Ciencias y sus aplicaciones (Revista semanal ilustrada. Tortosa 1914-1951), El imparcial (Diario político de la tarde. Madrid. 1867-1933), Journal of the American Oriental Society, La Codorniz (Revista de humor. Madrid. 1941 y sgts.), La Correspondencia de España (Diario universal de noticias 1855-1924), Madrid. (Diario de la noche. 1939 y sigs.), Madrid Científico (Revista decenal ilustrada de Ciencias, Ingeniería, Artes, Industrias, Curiosidades, etc. t. XVIII [1911] y XIX [1912]. Madrid), El Mundo Deportivo (Desde 1906 al servicio del deporte. Barcelona), Noticias de actualidad (Publicado por el Servicio de Informaciones de los Estados Unidos de América. Madrid 1953-1961), Noticiero español. La realidad de España(Madrid 1946-1951), El Noticiero Universal (Barcelona), Revista de la Biblioteca, Archivo y Museo (Ayuntamiento de Madrid 1924 y sigs.), La Revista Católica (Publicación quincenal. Santiago de Chile 1905 y sigs.), Revista del Centro de Estudios Extremeños (Barcelona. 1927 y sigs.), Revista de pesca marítima (t.1 Madrid 1885), La Vanguardia Española (Barcelona), Ya (Madrid. 1935-1936, 1939 y sigs.).

${ }^{14}$ Así, por ejemplo, el fascículo VIII (1968) incluye en su nómina Jornada (Diario de la tarde. Valencia 1941 y sigts), que no aparece recogido en el tomo primero. 
entradas de los verbos irregulares en las que las citas se emplean para ilustrar usos normativos y en ningún momento desviaciones de lo que se considera el modelo idiomático. Las menciones periodísticas contenidas en el siguiente fragmento y extraídas de géneros informativos (especialmente de noticias) se emplean para ilustrar usos no defectivos del verbo agredir, en consonancia explícita con las directrices académicas ${ }^{15}$ :

agredir. (Del lat. aggrēedi.) tr. Acometer o atacar a alguien para matarle, herirle o hacerle cualquier daño. Ú. t. en sent. inmaterial. Aunque la Academia en los diccionarios de 1927-1950(DM) y 1956 ha dado este verbo como defectivo, establece la supresión de esta nota en las Enmiendas y adiciones publicadas en el BRAE XLV 1965, 42. [...] 1953 Jornada [Valencia] 6 jun.: Agrede a su esposa y se suicida luego. 1956 Ac.: Agredido: p. p. de Agredir. Ú. t. c. s. $1965 A B C 19$ sept. $47 a$ : Los jefes de Misión de las grandes potencias están reunidos hoy [...] debatiendo [...] la actitud a tomar en el caso de que la China roja agreda a la India. (fascíc. VIII, 1968, página 1028a)

Así, pues, el Diccionario histórico del español ilustra ya con fuentes periodísticas uno de los aspectos de normatividad más recurrentes del uso del español en el discurso informativo actual: la defectividad e irregularidad de determinados verbos, tal y como pondrán de manifiesto los libros de norma lingüística posteriores en las referencias que hacen a la morfología verbal. En este sentido, conviene advertir de la tendencia en el discurso periodístico a convertir en regulares a verbos que tradicionalmente se tenían por defectivos en nuestro idioma (Pons y López 2011:545).

A la tarea lexicográfica desarrollada por la Academia hay que sumar la labor gramatical también emprendida desde los orígenes. En sus primeros estatutos, la Academia expresaba su intención de elaborar una gramática una vez terminado el diccionario. La

\footnotetext{
${ }^{15}$ El verbo abolir, que presenta problemas de normatividad en el español actual, también es ilustrado con citas periodísticas: “abolir, avolir. (Del lat. abolēre.) La forma avolir sólo se registra una vez. V. acep. 2a, pasaje del Dicc. Terreros 1786. 1. tr. Olvidar, perdonar. [...] 2. Suprimir usos, costumbres, leyes, instituciones, derechos, privilegios, etc., mediante actos de la voluntad, generalmente de carácter público, expreso y solemne. [...] 3. Dejar de usar algo, con el cambio del gusto y de las modas, y por la evolución natural de los tiempos. 1737Diario Literatos II 66: Siguióse al dominio de los Romanos el de los Godos y otras Gentes, que introduxeron sus lenguas, sin abolir la Romana”.
} 
primera edición, titulada Gramática de la lengua castellana, se publica en 1771. El cuerpo doctrinal de esta gramática, en la que apenas hay citas de autoridad, se fundamenta más bien en la reflexión que de la lengua y su uso hacen los gramáticos. Así, frente a lo que ocurre con las gramáticas modernas, en las que numerosos ejemplos literarios ilustran las explicaciones gramaticales, llama la atención que la Gramática de 1771 emplee las autoridades literarias para censurar usos desterrados de la lengua culta, bien por considerarse arcaísmos, bien por no ser valorados como usos prestigiosos.

Las reformas gramaticales que se hicieron en el siglo XIX sí hacen pensar en un ideal de lengua basado en la lengua literaria ${ }^{16}$, pues fue aumentando progresivamente el número de estos ejemplos (algunas llegaron a publicar un listado de autoridades), hasta llegar a la Gramática de 1931, de la que ya puede decirse que es una verdadera "Gramática de autoridades", según se hace explícito en el propio prólogo:

Lo que sí ha variado fundamentalmente [en esta edición de la Gramática], radicalmente podríamos decir, es, no el concepto del contenido de la Sintaxis, pero sí el método y plan de exposición de la doctrina sintáctica, y hasta la forma misma de esa exposición, que en la edición presente es más lógica, más razonada que en las anteriores; además la doctrina gramatical se presenta confirmada por mayor número de autoridades de los más eminentes escritores españoles de todas las épocas (RAE 1931: 5-6).

La autoridad literaria en la Gramática de 1931 se emplea fundamentalmente para documentar usos contemporáneos (aunque en ocasiones puntuales también se utiliza para atestiguar arcaísmos) $)^{17}$. Predominan los textos del Siglo de Oro, siguen los del XIX y, a mayor distancia, los del XVIII. No hay referencia, pues, a ejemplos extraídos de publicaciones periódicas, con lo que es posible deducir que la lengua periodística no

\footnotetext{
${ }^{16}$ A diferencia de lo que ocurrirá con la Nueva Gramática de la lengua española (2009), en la producción gramatical de la Academia los autores de los que se toman los ejemplos aducidos responden mayoritariamente a un canon literario de excelencia y no de representatividad dentro del ámbito hispánico.

17 "Y no faltan ejemplos de haberse usado en plural algunos otros vocablos de esta misma índole con el simple aditamento de la $s$. Los que finalizan con la letra $e$ acentuada también hicieron, por punto general, su plural en es en otros tiempos, y así Calderón, en La Dama Duende, jornada III, escribió: Ceáticas son estas cees; [...]" (RAE 1931: 18).
} 
era sentida aún como modelo digno de imitación por la preceptiva gramatical académica.

La publicación en 1973 del Esbozo de una nueva gramática de la lengua española, supone ya una renovación en la selección de los modelos literarios. Siguen estando presentes los escritores del Siglo de Oro pero estos constituyen solo una pequeña proporción del corpus utilizado, formado fundamentalmente por autores del siglo XX. Cabe destacar dos novedades de esta publicación. La primera tiene que ver con un cambio en la concepción de la norma ya que, al incluir a escritores hispanoamericanos, esta se vuelve más panhispánica. La segunda modificación afecta directamente a la lengua periodística, que por primera vez se tiene en cuenta como modelo digno de ejemplificación en la descripción gramatical. Las explicaciones del Esbozo contienen en ocasiones referencias a la ejemplificación del Diccionario histórico, que es retomada para completar o matizar la información que allí aparece. Es lo que ocurre en el siguiente ejemplo a propósito del verbo agredir:

El Diccionario Histórico de la Lengua Española (fascíc. VIII, 1968, página 1028a) cita dos formas fuertes de agredir con e, una de la publicación Jornada (Valencia, 6-VI-1953): agrede, y otra del diario $A B C$ (19-IX-65, página 47a): agreda. A estas formas fuertes de agredir, cultismo adoptado en las postrimerías del siglo XIX (lat. aggredi), habría que agregar agride ( $A B C$, I-III-1958, pág. 36) y agriede (B. Soler, en $A B C, 5-\mathrm{V}-1955$, pág. 3). Se ve que la variación vocálica e/i y la concurrencia de las variaciones vocálicas e/i, e/ieno han dejado de actuar cada una por su lado en el desarrollo de agredir, como era de esperar, dado que a todos los verbos de estructura -e-ir, con la sola excepción de los regulares convergir, divergir y sumergir, se extiende una u otra de dichas variaciones. Después de todo, agrideyengríe serían formas gramaticalmente gemelas si las dos proceden de una raíz común, lo que no es seguro (Esbozo, nota 107 , pág. 312 ).

Cabe señalar, sin embargo, que, a pesar de que el Esbozo recoja como fuente de datos algunas publicaciones periódicas, las referencias a ellas son muy esporádicas. En el rastreo efectuado por los diferentes capítulos que componen la obra (que carece de nómina de textos citados) se han encontrado solo tres publicaciones periódicas (si exceptuamos las citadas a partir del Diccionario histórico): el diario Ahora, Abc de 
Madrid y El Mundo de Puerto Rico. En los tres casos los textos ilustran la pauta gramatical (y no desviaciones normativas) ${ }^{18}$ y en dos ocasiones se sitúan junto a ejemplos extraídos de obras literarias. La disposición yuxtapuesta y sin matices entre la ejemplificación literaria y la periodística para ilustrar una determinada estructura lingüística o un uso idiomático concreto da cuenta de una valoración también pareja en cuanto a la condición de discursos propios de la distancia comunicativa ${ }^{19}$. Los siguientes dos ejemplos hacen referencia respectivamente al empleo del presente histórico para referir acontecimientos pasados y a la concordancia verbal exigida en las correferencias con el verbo subordinado en indicativo (ilustradas a partir de citas de discursos reproducidos indirectamente):

El presente histórico es, por su significado, evocación de un hecho pasado y concluido (perfecto). Así se explica también que aparezca en relatos literarios de sucesos inventados: Abren la puerta brazos armados,/ Fieros puñales son levantados (Valle-Inclán, La pipa de Kif: El crimen de Medinica); e igualmente en títulos periodísticos de hechos ocurridos en un pasado próximo: Un anciano octogenario es atracado y robado por unos desconocidos (Del diario Ahora, 3IV-1935)" (RAE 1973: 452).

3.19.6. Concordancia de los tiempos.- Para formular las reglas de la concordancia de los tiempos en nuestra lengua, distinguiremos dos casos: $1^{\mathrm{o}}$,

\footnotetext{
18 "La labor de codificación gramatical llevada a cabo por la Academia durante todo el siglo XVIII y gran parte del XIX no tuvo una intención normativa, en el sentido que hoy se le da a este concepto. Sorprende que en sus tratados gramaticales no hubiera costumbre de señalar variantes incorrectas, coexistentes con las normativas, que fueran objeto de censura. Sólo la Gramática de 1880 (casi idéntica a la de 1885) a través de un capítulo especial llamado "De los vicios de dicción" introduce de forma brusca esta idea de censura de la incorrección que se repite en sucesivas ediciones y no desaparece hasta el Esbozo (Borrego 2008)" (Méndez 2012: 284).

${ }^{19}$ El presente trabajo toma como marco teórico el modelo de análisis de Koch y Oesterreicher (1990[2007]), que distingue entre el lenguaje de la inmediatez comunicativa (oralidad) y el lenguaje de la distancia (escrituralidad) basándose en una concepción más o menos formal del discurso. Según estos autores, las modalidades lingüísticas se sitúan en una escala limitada por dos polos opuestos: la inmediatez y la distancia comunicativa. Ambos se identifican con oralidad y escrituralidad respectivamente, conceptos que pertenecen al ámbito de la concepción (en el sentido de más o menos formal) y que son independientes del medial, que se refiere al canal fónico-auditivo (oral) o gráfico-visual (escrito) por el que se transmite el mensaje. La habitual identificación entre los planos oralidad-oral y escrituralidad-escrito se explica porque lo más frecuente es que los modelos de la inmediatez utilicen la realización fónica pasajera frente a los pertenecientes a la distancia, más afines a la gráfica perdurable.
} 
verbo subordinado en modo indicativo; $2 .^{\circ}$, verbo subordinado en subjuntivo. 1. . Verbo subordinado en indicativo. - a) Puede usarse cualquier tiempo en el verbo subordinado, menos el pretérito anterior, lo mismo si el principal está en presente, que si está en pasado o en futuro; [...] Ejemplos: Sin conocerlo, se le respetaba; uno sabía que podía fiarse de él (F. Benítez, El Rey Viejo: La noche de los asesinos); El observatorio anunció que se acerca a nuestras costas un huracán en dirección NE a SO; el parte meteorológico añadía que las primeras ráfagas alcanzarán probablemente a nuestra isla esta madrugada (Del diario El Mundo, Puerto Rico, agosto de 1958) (RAE1973: 518-519).

El discurso periodístico también comparte espacio en la ejemplificación gramatical del Esbozo con textos extraídos de obras no literarias pero valoradas como pertenecientes a la distancia comunicativa, como ocurre con las referencias a la Gramática de Bello y con las expresiones construidas introspectivamente por el propio gramático para ilustrar la pauta:

Expondremos la subordinación sustantiva distribuyendo la materia en los apartados siguientes: $1 .^{\circ}$, oraciones sujeto; $2^{\circ}$, oraciones complementarias directas, y $3 .^{\circ}$, oraciones complementarias de un sustantivo o adjetivo. 3.19.2. Oraciones sujeto. - a) Ser o poder ser sujeto de una oración es inherente a la categoría gramatical del sustantivo, o de cualquier palabra, frase u oración que desempeñe el oficio de sujeto. Las oraciones sujeto se introducen por medio de la partícula anunciativa que. Ejemplos: Que el Papa expresara su preocupación por cuantos sufren...es más que seguro y responde perfectamente a su misión. Que el Papa se mostrara deseoso del triunfo de la paz es norma fundamental de su pensamiento y de su apostolado (Del diario $A B C$, 5-VII- 1970, pág. 19a). Dos o más oraciones coordinadas sujeto, introducidas por que, conciertan en singular; v. gr.: No es posible que se cometan crimenes impunemente y que la sociedad prospere (Bello, Gramática, § 829. Si la oración sujeto es interrogativa indirecta, no lleva que, porque los pronombres o adverbios interrogativos asumen el papel de nexo: Cómo y cuándo se ultimó el negocio no importa a nadie" (RAE 1973: 514-515).

En 1981 la Academia confió a Emilio Alarcos la redacción definitiva de la Gramática, tarea completada a principios de los noventa pero que, dado el particular planteamiento 
que presentaba, no se publicó finalmente como gramática académica sino como obra personal. La Gramática de Alarcos, aparecida en 1994 en la colección Nebrija y Bello, que patrocina la Real Academia Española, incluye numerosas citas para ilustrar las explicaciones gramaticales pero todas ellas son de carácter literario (págs. 391-394). No hay presencia, pues, de textos periodísticos en los ejemplos.

En 1999 se publica la Gramática descriptiva de la lengua española (GDLE), obra colectiva coordinada por Ignacio Bosque y Violeta Demonte. Aunque no es obra académica, constituyó un punto de referencia normativa autorizada debido al prestigio de los autores que intervinieron en la redacción de los diferentes capítulos y a la coordinación del académico Ignacio Bosque, de ahí que se haya tenido en cuenta para el análisis que nos proponemos. En la introducción que antecede a los capítulos de las cinco partes que componen la obra (1999: XXI), se afirma que se trata de una gramática descriptiva por varias razones: presenta las propiedades de las construcciones y de las palabras que las forman, expone y razona el comportamiento de las categorías gramaticales, se centra en la caracterización de problemas empíricos y, finalmente, muestra los datos que resultan necesarios para entender cada construcción. En relación a este último punto, la propia Gramática pone de manifiesto que las fuentes que se han utilizado para ilustrar la especulación gramatical de los diferentes capítulos que conforman la obra son autores literarios, textos periodísticos y, especialmente, la propia introspección de los autores. Hay, pues, una intención explícita de abrir el corpus de textos en consonancia con la vertiente descriptiva de la obra:

Los autores no fueron constreñidos sobre las fuentes de datos que debían manejar, pero sí fueron instados a hacer uso del mayor número de ellas. Como en las gramáticas colectivas de otros idiomas [...], la fuente principal de datos ha sido la instrospección [sic], lo que permite, como es bien sabido, usar 'datos negativos', es decir, secuencias agramaticales cuya inexistencia muestra alguna pauta consistente en el sistema gramatical. En este punto hemos actuado en esta obra como lo hicieron los autores de las gramáticas colectivas citadas. Sin embargo, frente a algunas de ellas, en la nuestra se hace uso habitual de fuentes literarias y periodísticas, corpus diversos privados o públicos y diccionarios sintácticos, fundamentalmente el de R.J. Cuervo. De hecho, esta es una de las 
gramáticas descriptivas del español moderno que más uso hace de fuentes distintas de la propia introspección" (GDLE 1999: XXIX).

Esta referencia explícita a la fuente de datos no se corresponde, sin embargo, con la existencia de una nómina concreta de textos empleados en la ejemplificación. Cabe señalar en este sentido que esta gramática, salvo alguna excepción ${ }^{20}$, no explicita el corpus del que parten los diferentes autores para la especulación gramatical. Así, prácticamente hay que ir capítulo por capítulo para ver en cuáles se manejan datos de los medios de comunicación, en cuáles literarios, en cuáles casi todos son inventados...

La presencia de ejemplos extraídos de los medios de comunicación aumenta notablemente en el DPD (2005) que, aunque no es propiamente una gramática, contiene normas gramaticales que orientan al usuario sobre aquellas partes de la lengua española que suelen generar mayor incertidumbre en los hispanohablantes. En consonancia con el carácter panhispánico de la obra, manifestado en su propio título, no resulta extraño que en la nómina de publicaciones periódicas (2005: 842-848) figuren periódicos y revistas tanto de España como de Hispanoamérica ${ }^{21}$. En proporción a los textos literarios, la presencia de fuentes periodísticas es muy inferior. Se ha contabilizado un total de 161 publicaciones periódicas escritas de las que 97 pertenecen a medios no españoles. Cabe añadir como novedad que el $D P D$ incluye también bajo el epígrafe "Citas de transcripciones del corpus oral de la RAE” (2005: 848) una representación mínima de siete programas de radio y televisión de carácter periodístico, de los que cuatro son españoles: A vivir que son dos días (Cadena SER. España. 1996), Encuesta 112 (Paraguay. 1993), Entrevista (CSHC-87. Venezuela. 1987), Protagonista (Onda Cero. España. 1997), El martes que viene (TVE 1. España. 1990) y Si yo fuera presidente (TVE 2. España. 1983).

\footnotetext{
${ }^{20}$ El capítulo 29 de Rafael Cano sobre "Los complementos de régimen verbal” sí hace explícita la nómina de textos citados, entre los que figuran varias publicaciones periódicas (además de textos literarios): Diario de Córdoba (Córdoba), El Adelanto (Salamanca), El Correo Gallego, El País, Ideal (Almería), La Crónica (Almería), La Jornada (México), La Prensa (México), La Voz de Almería, La Voz de Galicia, Sur (Veracruz, México) y Uno más uno (México).

${ }^{21}$ Las fuentes de datos no son solo periódicos nacionales y locales de todo el ámbito hispánico sino también revistas especializadas en diferentes áreas temáticas y boletines institucionales. La mayoría de los textos son citados de forma indirecta a través del Corpus de Referencia del Español Actual (CREA).
} 
La NGLE publicada en 2009 (dos volúmenes para morfología y sintaxis y el tercero para fonética y fonología de 2011), supone una renovación en los planteamientos codificadores de una institución como la Real Academia Española (Méndez 2013) que se fija como objetivo fundamental en esta obra describir pormenorizadamente las numerosas estructuras que son compartidas por la mayor parte de los hispanohablantes, precisando su forma, su significado y su estimación social, así como dar cuenta de las opciones particulares que pueden proceder de alguna variante diferente a esta estructura común en el ámbito europeo o hispanoamericano, tenga o no la consideración de variante ejemplar en su respectivo ámbito geográfico. La transformación en los planteamientos teóricos (Narbona 2013) que subyace en la especulación gramatical de esta obra se refleja también en las fuentes empleadas, que aumentan la diversidad de tipos de textos incluidos en la nómina en consonancia con el deseo de no reflejar solo usos ejemplares sino de dar cuenta también de la variación en sus distintas manifestaciones. Así, conviene tener en cuenta que, aunque no se abandona la ejemplificación construida por el gramático de forma introspectiva, los textos empleados en la ejemplificación de la $N G L E$ se abren a tipologías no presentes anteriormente en los tratados gramaticales, como ocurre con los textos orales, aunque estos tengan una presencia minoritaria en proporción a los escritos ${ }^{22}$ :

La Nueva gramática de la lengua española combina las dos fuentes de datos características de los tratados gramaticales clásicos: ejemplos construidos por sus redactores (en nuestro caso, siempre debidamente convalidados por un número suficiente de hablantes nativos y refrendados por las Academias) y ejemplos procedentes de textos. El corpus del que se han extraído los datos que ejemplifican aquí las estructuras gramaticales es uno de los más extensos de cuantos hayan sido nunca utilizados en un estudio lingüístico sobre el español. Contiene textos literarios, ensayísticos, científicos, periodísticos $\mathrm{y}$, en proporción menor, también otros de procedencia oral. Abarcan todas las épocas

\footnotetext{
${ }^{22}$ Los datos proceden por norma general de la lengua escrita, ámbito en donde opera la lengua estándar y, en menor medida, de la lengua oral: p. e., el 90\% de datos del CREA son de lengua escrita; de estos datos el 50\% se corresponde con autores de procedencia española y el otro 50\% con autores americanos que se reparten en proporciones diversas las áreas lingüísticas del español en América (Méndez 2013).
} 
y todos los países hispanohablantes, pero, como es lógico, son mucho más numerosos los procedentes de obras publicadas en el siglo xx (NGLE XLIV).

De este modo, las fuentes literarias siguen teniendo una amplia presencia en la $N G L E$ pero, a diferencia de lo que ocurría con la preceptiva académica tradicional, la autoridad literaria ya no obedece en general a un canon de excelencia (y, por lo tanto, no parece conveniente seguir llamándola propiamente 'autoridad') sino de representatividad idiomática:

La historia de la lengua literaria es una parte importante de la literatura (y entronca, además, con la historia de las ideas estéticas), pero sus objetivos no pueden confundirse con los que persigue un tratado gramatical descriptivo y normativo. Los autores de quienes se toman los ejemplos aducidos no son propuestos exactamente en cuanto auctores imitandi, tal como sostenía Nebrija en su Gramática castellana (1492): «los poetas $i$ otros autores por cuia semejança avemos de hablar». En efecto, muchos de los que figuran en la nómina no han sido seleccionados tanto en función de un canon literario de excelencia, explícito o implícito, cuanto como representantes de las variedades del español que ha sido posible documentar y analizar. Con todo, la presencia de determinadas construcciones en clásicos antiguos y modernos o en escritores de prestigio se considera un testimonio significativo de su difusión en la lengua culta y un aval de su integración en los registros formales. A su vez, ha sido necesario acudir, en buen número de casos, a ciertas obras narrativas por el simple hecho de que presentan variedades del español popular que era necesario atestiguar - por lo general, puestas en boca de diversos personajes-, y no, en cambio, porque se entienda que tales usos sean dignos de imitación (NGLE XLV).

Del texto anterior se deduce que la referencia a autores literarios en la $N G L E$ obedece más bien a un criterio de representatividad de la variedad lingüística empleada tanto para ilustrar el estándar de una determinada zona como variantes lingüísticas no ejemplares, en consonancia con la función que tienen los datos extraídos de las fuentes periodísticas, que a diferencia de lo que ocurría en el $D P D$, son exclusivamente escritas. Así, de los 361 textos citados en el epígrafe "prensa y otras publicaciones periódicas" (2009: 3796-3798), hay un total de 221 que pertenecen a medios no españoles, 
fundamentalmente hispanoamericanos (también se recogen puntualmente periódicos editados en EE.UU).

El análisis efectuado en el recorrido histórico por la preceptiva académica permite establecer un cambio radical en la nómina de textos empleados en la reciente producción normativa de la institución que, además de textos literarios y de ejemplos construidos introspectivamente por el propio gramático, ha incrementado notablemente la presencia de la lengua de los medios. Ahora bien, cabe plantearse si este salto cuantitativo en la nómina de fuentes empleadas en la ejemplificación conlleva un cambio en la valoración de esos textos, es decir, si su función continúa siendo la de ilustrar la pauta normativa, como ocurría en el Esbozo, o, por el contrario, subyace una idea de censura más o menos implícita hacia la incorrección ilustrada con las citas de prensa.

3. La ejemplificación periodística en la reciente producción gramatical de la Real Academia Española: función y valoración normativa

El análisis de la función que cumple la ejemplificación periodística empleada en la producción gramatical académica no puede desligarse del estudio de la formulación metalingüística que contextualiza las muestras extraídas de los textos que constituyen la nómina de fuentes, puesto que esta refleja - a veces de manera velada e indirecta- la valoración normativa que subyace a determinados usos idiomáticos. Casi nuca se emplean los calificativos correcto o incorrecto en la redacción que precede a la ilustración, ya que la crítica no se materializa normalmente de forma tan categórica. De ahí que se empleen expresiones más matizadas que sirven de indicadores de los criterios de vigencia, extensión, frecuencia y valoración de un determinado fenómeno.

Antes de acometer el estudio, cabe plantearse dos cuestiones que han de tenerse en cuenta en el análisis concreto de las muestras de prensa obtenidas de la ejemplificación del $D P D$ y de la $N G L E^{23}$. En primer lugar, ¿qué tipo de género periodístico (noticia,

\footnotetext{
${ }^{23}$ Con el objetivo de establecer un contraste con otras fuentes normativas de referencia anteriores, se utilizarán puntualmente muestras extraídas de la $G D L E$, a pesar de no ser obra de la Academia. Para ello,
} 
columna o artículo de opinión, crónica, entrevista...) es el que se emplea en la ejemplificación?; en segundo lugar, conviene plantearse si los textos periodísticos son utilizados exclusivamente como ejemplos de discursos de la distancia comunicativa, como ocurría con las fuentes literarias entendidas como autoridad o, por el contrario, estos textos de prensa se emplean también para ilustrar variantes lingüísticas no estándares en un determinado territorio $\mathrm{y}$, por lo tanto, como muestras de usos idiomáticos no ejemplares, en consonancia con la vertiente descriptiva de la normativa académica $^{24}$. Ambas cuestiones están íntimamente relacionadas, ya que los géneros periodísticos de opinión ilustran con más frecuencia usos no ejemplares ${ }^{25} \mathrm{o}$ de carácter

se han realizado varias calas en aquellos capítulos $(1,21,22,25,26,27,29)$ que recogían los problemas de normatividad asociados habitualmente a la lengua de los medios de comunicación: concordancia, morfología y régimen verbal, formación de género y número, problemas sintácticos en el empleo de los pronombres átonos de tercera persona, construcciones impersonales...

${ }^{24}$ En el siguiente texto, extraído del apéndice final de la $N G L E$ (2009: 3719), la aparición del conector pero sirve para contraponer los usos de la lengua culta en el registro formal comunes a todo el ámbito hispánico (y ejemplificados en citas de autores literarios clásicos) a las muestras de lengua procedentes de otros autores (que no representan ya un canon de excelencia) y de los textos periodísticos. La intención de la gramática académica es que estos últimos sean empleados para representar variedades específicas de determinadas zonas del mundo hispánico, se correspondan o no con usos ejemplares en sus respectivos espacios variacionales: «Tal como se explica en el Prólogo, los autores de quienes se toman los ejemplos aducidos no constituyen propiamente, en su conjunto, un canon de excelencia. En esta Nómina, como es lógico, figuran numerosos clásicos hispánicos de todos los tiempos, así como otros autores que, sin haber alcanzado ese rango, gozan de prestigio reconocido. La presencia de ambos grupos en la Nueva gramática documenta los usos de la lengua culta y avala la integración de sus construcciones gramaticales en los registros formales de la lengua. Pero [el subrayado es nuestro] junto a ellos aparecen otros autores - de obras de creación o de libros de múltiples temas, en bastantes casos de gran difusión popular- que simplemente documentan variedades del español en las distintas áreas lingüísticas o en los diversos niveles de realización de la lengua, que aquí se analizan y valoran desde la perspectiva de la norma hispánica. Especial significación tienen en este último grupo los textos de prensa y otras publicaciones periódicas de todo el mundo hispanohablante que la Red universaliza» (NGLE 2009: 3719).

${ }^{25}$ Así, las columnas y los artículos de opinión son más proclives a incorporar mecanismos coloquiales con los que se "refuerza la proximidad de la relación entre los interlocutores" (Mancera 2008: 478). Dentro del género de opinión, el editorial, dado su carácter institucional, se presta menos a estos recursos y se suele articular dentro de los límites expresivos del estándar. El reflejo de la variación lingüística en el discurso periodístico queda asociado, no obstante, a otros parámetros (no vinculados al género informativo) que inciden directamente en el empleo de rasgos no considerados estándares y que tienen que ver con el soporte (oral o escrito) por el que se transmite la información, la sección periodística en la que se clasifique la materia (la información deportiva es más permeable al empleo de formas coloquiales) y, finalmente, el grado de trascendencia, formalidad o especialización del tema tratado (Méndez y Leal 2007, Vellón 2013: 21-22). 
no panhispánico frente a lo que ocurre con los géneros informativos, que se articulan casi de forma exclusiva dentro del marco expresivo del estándar ${ }^{26}$.

Dejando a un lado los casos en los que las citas periodísticas reflejan usos poco frecuentes o meramente testimoniales ${ }^{27}$, lo habitual es que estas muestras se utilicen como modelo de construcciones ejemplares. En otras palabras, los textos extraídos de las publicaciones periódicas se emplean mayoritariamente en la preceptiva académica para ilustrar las pautas, reglas o normas derivadas del proceso analítico de teorización gramatical basado en la conceptualización y establecimiento de categorías. Se constituyen, pues, como paradigma de corrección idiomática y como referencia para la valoración normativa, de ahí que estén antecedidos por expresiones del tipo "se comprueba en los siguientes ejemplos". Las citas de prensa confirman, pues, la veracidad de la pauta académica ${ }^{28}$ y se inscriben en lo que "debe ser" de acuerdo a los usos prestigiosos, al igual que las fuentes literarias, a las que con frecuencia aparecen yuxtapuestas en la ejemplificación. En este sentido, los siguientes ejemplos se limitan a dar testimonio de los principios normativos que regulan (a) el uso de los pronombres

\footnotetext{
${ }^{26}$ Esta vinculación histórica entre género periodístico y estándar tiene que ver con una serie de rasgos identificativos de la función comunicativa de los medios. Entre ellos, destacan la función social vinculada al carácter supradialectal del estándar, la identificación entre variedad "neutra" y objetividad (frente a variación estilística y subjetividad u opinión) y el prestigio asociado a lo ejemplar: "El modelo de lengua transmitido por los libros de estilo, sin apenas concesiones a lo que se aleje de la variedad única dominante, dista mucho de lo que es la práctica textual en los diarios y en los informativos actuales. Aun muy lastrados por las convenciones de la denominada ideología del estándar, siguen optando por mantener la identidad informativa del discurso periodístico en torno a la variedad neutra como exponente de la retórica de la objetividad que mantiene su valor caracteriológico de prestigio" (Vellón 2013: 25-26).

${ }^{27}$ Como ocurre con la forma maravedises, de raigambre popular y poco empleada ya en las áreas rioplatense y andina: "Las cortes de 1586 confirmaron esta resolución conciliar, y Felipe II puso en rigor la ley respectiva bajo la pena de tres mil maravedises" (Caretas 18/1/1996) (NGLE 2009: 133). También se ilustra con una cita periodística ("Se vinculó a grandes conjuntos de los países aquende la cortina de hierro (Tiempo [Col.] 14/1/1975)") el adverbio aquende, escasamente usado en la lengua actual (NGLE 2009: 1320-1321).

${ }^{28}$ Esta función es habitual también la GDLE, como puede observarse en relación a la alternancia en el régimen preposicional de determinados verbos: "El régimen con en es exclusivo con determinados verbos de actitud mental, en los que viene a señalar el objetivo de dicha actitud: confiar y creer $[\rightarrow \S \S 10.8 .4$ y 32.4.1.4]; con ellos es posible también el régimen directo, [...]. Con régimen, ambos verbos equivalen a «tener fe en»: [...] b. Confia el PRT en recuperar el registro definitivo como partido [Jornada, 16] (1999: 1827).
} 
átonos de tercera persona ${ }^{29}$, (b) la interpretación prospectiva del pretérito perfecto compuesto de subjuntivo o (c) determinados usos de la concordancia:

(a) Los pronombres le, les proceden, respectivamente, de las formas latinas de dativo illi, illis. El dativo es el caso de la declinación latina en el que se expresaba el complemento indirecto. Por ello, la norma culta del español estándar establece el uso de estas formas para ejercer dicha función, independientemente del género del sustantivo al que se refiere el pronombre: «Conocí a un cirujano plástico a quien le conté mi problema» (Tiempo [Col.] 1.12.87) (DPD: 2005. "Leísmo").

El complemento de persona es indirecto con los verbos permitir, prohibir, proponer, impedir, mandar y ordenar: [...] «Le prohibió salir de la capital hasta nueva orden» (Tribuna [Hond.] 18.6.97); [...] «La Policía les ordenó que no lo hicieran» (Clarín [Arg.] 18.4.97). (DPD: 2005. “Leísmo”).

Los pronombres la, las proceden, respectivamente, de las formas latinas de acusativo illam, illas. El acusativo es el caso de la declinación latina en el que se expresaba el complemento directo. Por ello, la norma culta del español estándar solo admite el uso de estas formas para dicha función: [...] «Estas cosas muchos no las quieren creer» (Vanguardia [Esp.] 6.7.94). (DPD: 2005. “Laísmo”).

(b) “Añadió que espera que en un futuro próximo Irán haya resuelto el problema de los rehenes (El País [Esp.] 17/12/1980); Costas ha solicitado que para cuando se haya terminado el proyecto, el Ayuntamiento haya preparado un plan que permita erradicar la totalidad de las chabolas allí levantadas (Canarias 19/9/1996)" (NGLE 2009: 1802).

(c) "Si los elementos coordinados se refieren a una misma cosa o persona, el verbo irá necesariamente en singular: «La actriz y cantante está bastante molesta» (Universal [Ven.] 17.4.88). Si los elementos coordinados son gramaticalmente neutros, como infinitivos, oraciones sustantivas o pronombres neutros, el verbo va en singular: «No creo que sumar y restar sea lo suyo» (Sierra Regreso [Esp.

\footnotetext{
${ }^{29}$ Posteriormente se analizarán los casos de laísmo, leísmo y loísmo a partir de textos periodísticos.
} 
1995]); «Le gusta que la quieran y que la apoyen» (Tiempo [Esp.] 3.12.90); «Ni aquello $\quad$ ni esto hubiera sido posible» (Abc [Esp.]25.1.85)". (DPD "Concordancia": 2005).

El valor normativo asociado a la lengua de los medios de comunicación hace que en la conceptualización teórica de la $N G L E$ aparezcan algunas explicaciones para justificar un determinado comportamiento lingüístico en el que se atribuye a los medios la función estandarizadora sobre variantes no ejemplares circunscritas a determinados ámbitos geográficos. Así, el retroceso en Andalucía occidental del empleo de ustedes en lugar de vosotros como tratamiento de confianza se atribuye en el siguiente fragmento a la presión niveladora ejercida por los medios:

El área andaluza a la que se hace referencia [...] abarca fundamentalmente las provincias españolas de Huelva, Sevilla, Cádiz y Málaga, así como algunas partes de Jaén y Córdoba. No obstante, en los últimos años se ha detectado un crecimiento de vosotros/vosotras a costa de ustedes en estas áreas, probablemente motivado por la intensa influencia de los medios de comunicación (NGLE 2009: 193) ${ }^{30}$.

Dentro del marco de usos normativos, la $N G L E$ recoge y analiza usos lingüísticos propios de los medios de comunicación. Es lo que ocurre, por ejemplo, con el "condicional de rumor", que se emplea como mecanismo de discurso referido para introducir una cita encubierta con la que el emisor (periodista) no se hace responsable de la verdad de lo enunciado (Méndez 1998 y 1999a). La ejemplificación que ilustra este uso, variante del condicional de conjetura que presenta información de forma cautelosa o no suficientemente contrastada, está extraída de publicaciones periódicas tanto en el empleo del condicional simple ("Se trata, en suma, de evitar que haya partidos que vean en la aprobación de la propuesta autonómica de CIU el precio que el Gobierno estaría [= 'probablemente está o estaba'] pagando a cambio del apoyo de los

\footnotetext{
${ }^{30}$ La expresión impersonal en la que aparece expresada esta afirmación "se ha detectado" no permite establecer qué datos ha empleado la Academia para realizar tal aseveración, más aun cuando el uso de "ustedes" familiar sigue firme dentro de su área prototípica. Cabe plantearse, además, si la influencia para la nivelación normativa en el empleo de "vosotros" está relacionada más con la escolarización de la población que con la difusión de patrones idiomáticos a partir de los medios de comunicación.
} 
nacionalistas (Vanguardia [Esp.] 21/4/1994). pág. 1782) como en el compuesto ("Dos periódicos argelinos daban cuenta ayer de una operación en la que habrían [= 'probablemente habían'] muerto más de 400 militantes (Mundo [Esp.] 15/10/1995). págs. 1794-1795).

La mayor frecuencia de una determinada estructura en la lengua periodística también se pone de manifiesto en la explicación del empleo de la forma pasiva del auxiliar en la perífrasis dejar de + infinitivo (NGLE 2009: 3045):

En la actualidad, se atestigua la opción de la forma pasiva del auxiliar en la lengua de la prensa con mayor frecuencia que en las demás variedades: El defoliante agente naranja, empleados en los bombardeos estadounidenses sobre Vietnam, y que fue dejado de utilizar en 1971, sigue contaminando el país (País [Esp.] 12/8/2003); Diariamente [...] se acumulan 1500 toneladas de basura, las cuales fueron dejadas de recoger en los últimos 15 días (Listín Diario 2/7/2002); Solamente en el condado de Miami-Dade, más de diez mil boletas fueron dejadas de contar (Granma 23/7/2002).

La preceptiva académica también pone de manifiesto una tendencia creciente en el idioma que cuantitativamente está asociada al discurso periodístico, al que se le otorga una cierta autoridad en la aclimatación de usos relativamente neológicos, como ocurre con la reciente productividad del prefijo macro-, con el empleo del sufijo -ble con base sustantiva o con los neologismos verbales formados a partir de sustantivos de otros idiomas y conjugados por la primera conjugación:

Hace ya seis años empezaron su andadura por el mundo del "macroespectáculo al natura" (ABC 25/6/1993) [...] La estructura se basa en cinco macroáreas (País [Esp.] 13/7/1999); La ONU ve así como se diluyen gran parte de las esperanzas depositadas en esta nueva macroconferencia para combatir el cambio climático (Diario Montañés 9/12/2007) (NGLE 2009: 732).

En la lengua actual se extienden los adjetivos derivados en -ble con bases sustantivas, especialmente con las que designan cargos, profesiones o dignidades [...] aumentan los derivados que corresponden a este grupo en el lenguaje de los medios de comunicación. He aquí algunas muestras: “[...]; Se habla también de algunos cardenales que fueron papables en los últimos cónclaves (País [Esp] 
10/3/1979) [...] A este grupo de rectorables se suman otros universitarios que han manifestado su interés por participar en el proceso de auscultación (Excélsior 1/11/1996) (NGLE 2009: 558-559).

Han ingresado en español cierto número de verbos en $\mathrm{N}$-ear derivados de sustantivos de otros idiomas, entre los que predomina el inglés. Se atestiguan sobre todo estos nuevos usos en el lenguaje del deporte (batear, boxear, golear, jonronear, noquear), en el de la informática (chatear, formatear, resetear) y en el de los medios de comunicación y reproducción gráfica (escanear, faxear, zapear) (NGLE 2009: 600).

Cabe señalar que las citas periodísticas en la $N G L E$ se acumulan en apartados que abordan la formulación lingüística de contenidos recurrentes en la materia informativa ligada a la actualidad, bien por tratarse de realidades que contextualizan referencialmente la información (topónimos, gentilicios, cargos, títulos, dignidades, fechas ${ }^{31} \ldots$ ), bien por constituir mecanismos productivos de carácter expresivo y condensado, como ocurre con el empleo de determinados sufijos. Así, de la redacción académica parece inferirse en ocasiones que determinados neologismos recurrentes en la prensa cuentan con legitimidad normativa en el ámbito periodístico:

Aunque -landia no tiene origen grecolatino, se asimila al grupo de las bases compositivas cultas para dar nombre a países o regiones (Finlandia, Groenlandia, Islandia). Su productividad es aprovechada por escritores y periodistas para designar territorios o mundos imaginarios, así como para nombrar de forma expresiva otros existentes (NGLE 2009: 786).

En la misma línea de permisividad normativa y de necesidad de condensación informativa, habría que señalar la productividad del sufijo - azo añadido a bases sustantivas con nombre propio como mecanismo para denominar acciones o decisiones políticas o administrativas con repercusión pública y de carácter sorpresivo y

\footnotetext{
${ }^{31}$ Véase el gran número de citas periodísticas concentradas en el apartado "Usos deícticos del artículo determinado. El artículo en las expresiones temporales” (NGLE 1999: 1066-1073).
} 
autoritario. En este apartado todos los ejemplos que refuerzan la explicación proceden de la prensa:

Alfonsí previó entonces que el "malvinazo" podía derivar en una tragedia para el país (Hoy [Chile] 28/12/1983); Los diarios dominicanos abordan temas como el narcotráfico, el día de la juventud, la desagregación de leyes impositivas en el presupuesto y los rumores para que se produzca en el país un "fujimorazo" (Dedom 31/1/1997); El 맘igazo alteró radicalmente la distribución del ingreso en desmedro de asalariados y clase media (Clarín 28/8/2005); El borocotazo en masa que se produjo en los últimos días [...] no hace más que confirmar la estafa que se pergeñó en las elecciones de octubre último (Nación [Arg.] 28/4/2006): Le llamaron el bogotazo a las revueltas y sangrientos saqueos que durante tres días sacudieron la capital (Provincias 28/12/2007) (NGLE 2009: 403).

En la línea de la especificidad del discurso informativo, también la $N G L E$ hace observaciones sobre la funcionalidad que un determinado uso lingüístico tiene en el ámbito periodístico. Así, la ausencia de determinantes en los titulares se vincula a la necesidad de condensación informativa:

[...], el lenguaje periodístico usa a menudo los grupos nominales escuetos como sujeto en el encabezamiento de las noticias, crónicas y reportajes. La tendencia a la omisión de determinantes es todavía mayor en el lenguaje telegráfico de los titulares de prensa utilizado por algunos medios de comunicación escrita, ante la necesidad de condensar la información noticiosa en un espacio muy limitado. Es característico de este registro escrito el uso de grupos nominales escuetos con sustantivo contable en singular: Alcalde desobedece una sentencia $(A B C$ 18/4/1989); Presunto delincuente hiere a dos policías (País [Esp.] 2/5/1980); Ministro de Defensa recibió grupo de psicólogos (Universal [Ven.] 17/4/1988) (NGLE 2009: 1151).

Las directrices normativas, más o menos rígidas, ilustradas con citas periodísticas, se concentran en las vacilaciones idiomáticas directamente relacionadas con cambios producidos en la realidad social. Es lo que ocurre, por ejemplo, en el capítulo que la $N G L E$ dedica al género. En un intento de cuantificar los datos, hemos efectuado un 
recuento que permita establecer un contraste entre los tipos de muestras empleadas ${ }^{32}$ en la ejemplificación de este capítulo y las utilizadas en otro de extensión aproximada perteneciente también a la morfología, nivel de análisis que presenta mayor número de citas periodísticas frente a la sintaxis: "El artículo (I). Clases de artículos. Usos del artículo determinado". Presentamos a continuación dos gráficas que recogen los porcentajes obtenidos en cada caso:

Fig. 1. Ejemplificación empleada en el capítulo 2 "El género". NGLE (2009: 81-126)

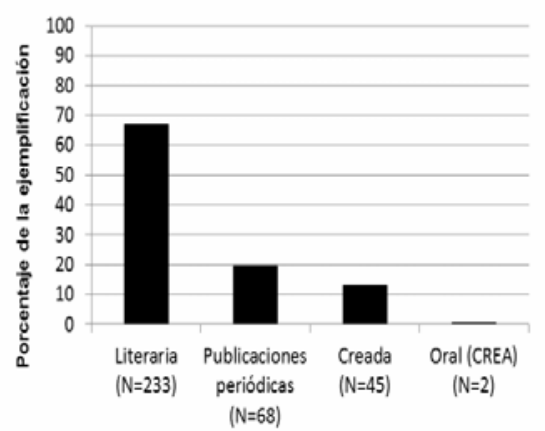

Fig. 2. Ejemplificación empleada en el capitulo 14 "El articulo (I)". NGLE (2009: 1023-1086)

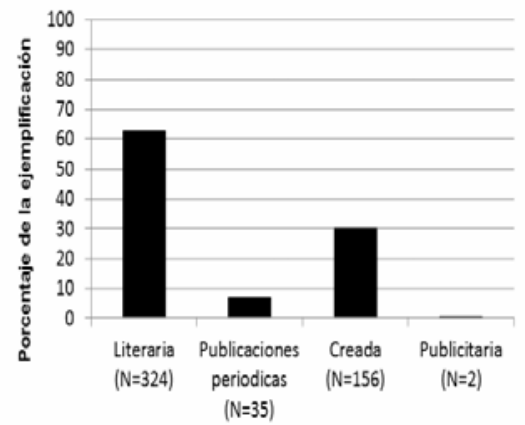

Los datos reflejan una presencia similar en los dos capítulos analizados de los ejemplos procedentes de fuentes literarias. No ocurre lo mismo, sin embargo, con las muestras periodísticas, que prácticamente se duplican en el capítulo dedicado género. La proporción de ejemplos creados introspectivamente por el gramático es notablemente superior (prácticamente el doble en porcentaje) en el capítulo del artículo.

Como se puso de manifiesto en los párrafos anteriores, la mayor presencia de muestras periodísticas en el capítulo del género se justifica por el hecho de que en él se recoge toda una serie de pautas normativas vinculadas a la formación del femenino en profesiones, cargos y títulos, con una gran casuística de alternancias y preferencias, así como orientaciones sobre la tendencia a las series coordinadas que tratan de evitar el uso del masculino genérico en determinados tipos de discurso, consideradas innecesarias por la preceptiva académica:

En el lenguaje de los textos escolares, en el periodístico, en el de la política, en el administrativo y en el de otros medios oficiales, se percibe una tendencia

\footnotetext{
${ }^{32}$ En el recuento se han contabilizado solo aquellos ejemplos que constituían estructuras oracionales gramaticales.
} 
reciente (de intensidad variable, según los países) a construir series coordinadas constituidas por sustantivos de persona que manifiesten los dos géneros [...]: Durante más de cuarenta años las niñas y niños colombianos han sufrido extrema violencia (Tiempo [Col.] 6/9/1996); Una masiva ovación de los diputados y las diputadas [...] cierra el presunto debate, ante la atenta mirada de los responsables de su grupo por si algún diputado o alguna diputada [...] aplaude con gesto tibio (País [Esp.] 2/4/1999) (NGLE 2009: 87).

De hecho, algunos de los ejemplos extraídos de publicaciones periódicas en el capítulo del artículo se refieren también a cuestiones vinculadas al género gramatical:

[...], en la actualidad se acepta la flexión de género en algunos sustantivos designadores de profesiones o cargos que tradicionalmente se habían considerado comunes en cuanto al género. Entre ellos se encuentra árbitro. Se decía, por tanto, la árbitro cuando se designaba a una mujer que desempeñaba tal función. En el $D R A E$ de 1984 aparece la forma árbitra como sustantivo. Aunque - de acuerdo con esta nueva adaptación - se esperaría la forma el árbitra (como el ama de llave o el aya), muchos hablantes han optado por conservar la otra variante (la árbitra), que se considera correcta. [...]: La árbitra pitó un penalti contra el Laguna (País [Esp.] 4/2/1999) (NGLE 2009: 1036).

La necesidad de precisión en la identificación de los referentes dentro del discurso informativo justifica las directrices normativas vinculadas a los sustantivos epicenos o a usos ambiguos del masculino genérico:

Cuando es necesario especificar el sexo del referente, se prefiere emplear los términos masculino y femenino, [...]: En la contraportada del álbum está la foto de un chico desmayado con la cara besuqueada, otra víctima masculina de las roqueras (País [Esp.] 2/2/1986) (NGLE 2009: 83-84).

[...], el contexto puede no dejar suficientemente claro, en casos muy específicos, que el masculino plural comprende por igual a los individuos de ambos sexos. Una opción posible es acudir en ellos a las fórmulas desdobladas, como en Los españoles y las españolas pueden servir en el Ejército. Otra opción es especificar la doble mención en alguna apostilla o mediante un modificador restrictivo que aclare la extensión del grupo nominal: [...] la libertad individual 
de los miembros de un Ejército que, a medio plazo, estará formado exclusivamente por profesionales, tanto hombres como mujeres (País [Esp.] 30/8/1997); Según la propuesta de ley que pretende presentar en la Cámara Alta, los primogénitos heredarán la Corona británica sea cual sea su sexo (Mundo [Esp.] 30/10/1996) (NGLE 2009: 87-88).

Las citas periodísticas se emplean, aunque en menor medida, en la reciente producción normativa académica, como muestras de diferentes estándares dentro del ámbito hispánico. Es lo que ocurre, por ejemplo, con la preferencia por los femeninos por moción en Hispanoamérica:

En España, bebé funciona generalmente como sustantivo epiceno masculino: «En la mochila de Carolina apareció un bebé muerto. La niña era de Carolina» (Mundo [Esp.] 20.11.96); en América, salvo en los países del Río de la Plata, tanto la forma aguda como la llana se usan a menudo como sustantivos comunes en cuanto al género: «Dijo que la bebé estaba viva» (Tiempo [Col.] 16.11.94); «Tanto la madre como la bebe fueron trasladadas al hospital» (DAméricas [EE. UU.] 14.4.97) (DPD).

También corresponde a ese grupo el par cónsul/consulesa en algunos países americanos en los que se usa la variante femenina: La consulesa, quien asumió sus funciones el 6 de abril pasado, es acusada de maltrato verbal y agresión física al oficial de dicha oficina (ABC Color 31/10/2000). En los demás, cónsul es común en cuanto al género: Según la cónsul de Colombia en Yakarta, [...] (Heraldo [Col.] 31/12/2004) (NGLE 2009: 92).

El sustantivo fiscal, procedente asimismo de un adjetivo (el tema fiscal), es común en cuanto al género (el fiscal/la fiscal), pero se registra también la forma fiscala, frecuente en el Paraguay y en otros países americanos, a veces en alternancia con el uso femenino de fiscal: La fiscala Vallejo detectó la reduplicación de pagos de viático (ABC Color 5/9/2001). Se usan asimismo los femeninos concejala (que alterna con la concejal), bedela (que alterna con la bedel) y otros similares (NGLE 2009: 104). 
Otros usos específicos de determinadas zonas del ámbito hispánico se presentan de forma menos sistematizada pero confiriéndoles el estatuto de estándar en su respectivo espacio variacional:

Con el sentido de sumamente, se usa supremamente en Colombia: Es supremamente riesgoso para el país (Tiempo [Col.] 13/9/1996) (NGLE 2009: 2303).

El verbo externar (derivado de externo) se usa en México, Centroamérica y las Antillas, entre otras áreas: Me dio la impresión de una extranjera común y corriente, reservada y fría al externar sus sentimientos (Nación [C. Rica] 23/1/1997) (NGLE 2009: 2604).

[...] Tampoco lo llevan [el artículo determinado] cuando el día de la semana se identifica por medio de una oración atributiva, como en Hoy es jueves o en Estamos a sábado. Esta última construcción es general en el mundo hispánico. La variante Estamos sábado es característica del Perú, donde también se usa la opción con preposición. [...]: Ya pasaron muchas horas, ya estamos sábado y deberíamos estar mejor organizados (Comercio [Perú] 19/8/2007) (NGLE 2009: 1068).

Las citas periodísticas se constituyen también en reflejo de alternancia de usos admitidos por la norma académica pero con diferente valoración asociada. En estos casos, se emplean expresiones del tipo "se recomienda" o "es preferible", como ocurre con la alternancia entre la forma invariable de un latinismo y la opción en $-\mathrm{s}$ en la formación del plural. Los medios de comunicación sirven de ilustración de ambas variantes: "Déjame alertarte que los ultimátums no siempre llevan al matrimonio" (Nuevo Herald 12/2/1997); el líder serbobosnio declaró “nulas" todas las resoluciones de la ONU, los ultimátum de la OTAN y los acuerdos negociados por la parte serbia con las Naciones Unidas (Mundo [Esp.] 30/5/1995) (NGLE 2009: 142). 
En el polo opuesto al empleo de las citas periodísticas como modelos ejemplares, se sitúa su uso como modelo antinormativo ${ }^{33}$. De este modo, los textos periodísticos pueden ejemplificar la aplicación errónea de una regla o pauta general ${ }^{34}$. Los

${ }^{33}$ La tendencia a emplear las citas periodísticas como contraejemplo a una pauta gramatical explicitada en el cuerpo doctrinal aparecía también en la GDLE. La redacción que antecede a estos ejemplos utiliza expresiones de tipo "contraejemplos a la generalización" (pág. 37), "las gramáticas del español deploran de forma unánime" (pág. 1689). Así, en relación a los rasgos de plural de los sustantivos colectivos y la concordancia verbal, se extrae toda una serie de ejemplos procedentes de publicaciones periódicas que contravienen la regla de que los sustantivos colectivos determinados concuerdan en singular: "Cuando la policía llegó al apartamento, se encontraron con la cómica, aunque desagradable escena de (...) [Revista Semana; citado en Fält 1972: 83] / Al estandarte de los Reyes Católicos (...) daban escolta una escuadra de infantería [ABC; citado en Fält 1972: 106] / La policía, sin embargo, a pesar de que siquiatras, astrólogos, y los más famosos detectives han sido movilizados, no tienen todavía pistas que (...) [ $\mathrm{La}$ Vanguardia; cit. en Fält 1972: 106] [...] El jurado manifestó que en su día ya habían solicitado la igualación de (...) [La Vanguardia; citado en Fält 1972: 108] (1999: 37-38). Otro de los usos en los que la presencia de ejemplos periodísticos se emplea como crítica a usos no normativos tiene que ver con la confusión entre las construcciones impersonales con se y la pasiva refleja: "La presencia del sintagma preposicional en la construcción impersonal es incompatible con la concordancia. Las gramáticas del español deploran de forma unánime oraciones como la muy citada Se azotaron a los delincuentes. Aunque la construcción no es muy común y aparece más extendida en el español de América que en el español peninsular, no faltan ejemplos que ilustren este caso; Sepúlveda (1988: 6.4.2) cita varios ejemplos de la prensa española peninsular: a) Mientras que en otros países, como Estados Unidos, todos los años se expulsan a centenares de agentes por la comisión de delitos [Cambio 16, ${ }^{\circ}$ 597, mayo 1983; citado en Sepúlveda 1988: 133]. b) Se han invitado asimismo a representantes de las centrales sindicales, y las organizaciones empresariales. [El País, 25-II-83; citado en Sepúlveda 1988: 133]" (1999: 1689-1690).

${ }^{34} \mathrm{La}$ tendencia a mostrar con la ejemplificación periodística infracciones normativas es la dominante en los manuales y libros que abordan de manera práctica las vacilaciones en la norma lingüística. Así, en el caso de las compilaciones de artículos recogidos en El dardo en la palabra (1997) y El nuevo dardo en la palabra (2003) se hace una crítica de usos vinculados al discurso periodístico. La representatividad de los ejemplos extraídos de los medios de comunicación es difícilmente cuantificable, dado que no se ilustran las infracciones normativas con referencias reales concretas identificables (día y publicación en la que aparece) sino que el autor o bien se hace eco de problemas de normatividad que considera generalizados o bien hace una referencia imprecisa al medio: "Un diario meridional, que me envía un lector y que elijo entre tantos, escribe en titulares: miercoles, Africa, jóven, ésto, un solo voto, además de elije" (Lázaro 2003: 77). La crítica, que es siempre explícita ("dígase cualquier cosa menos ésa"), incluye infracciones asociadas no solo a ejemplos escritos sino también a usos orales, lo que constituye una excepción en la tendencia dominante en la preceptiva académica. En este último plano son recurrentes las censuras al lenguaje radiofónico y a la lengua empleada en los informativos: "no pasa día sin que [televisiones] oficiales y privadas peguen quince o veinte arreones parecidos al idioma. Los dan en casi todos los programas, y son más de sentir, por su naturaleza, en los noticiarios [...]" (Lázaro 2003: 70). La serie de manuales normativos de Leonardo Gómez Torrego, que se inicia con el Manual del español correcto (1989), hace también explícita la censura a usos empleados en los medios de comunicación: "Dado el carácter abierto con que hemos concebido esta obra por ir dirigida a sectores muy heterogéneos de la sociedad, los vulgarismos o incorrecciones que en ella se tratan son de muy diversa índole: al lado de incorrecciones crasas solo detectables en capas sociales de poca cultura, aparecen otras relativamente frecuentes, más disculpables e, incluso, discutibles en las que suelen incurrir personas más o menos cultas y de gran proyección popular dada su profesión u oficio (locutores, periodistas, políticos...)" (Gómez 2004: 8). Pero estas incorrecciones a las que se alude no se ilustran en ningún momento con ejemplos reales sino construidos por el propio gramático a partir de la explicación teórica que pretenden ilustrar y en consonancia con el carácter escolar de la obra, acompañada de ejercicios prácticos. Esta misma 
mecanismos que se emplean para contextualizar y valorar estos casos son muy diversos en cuanto a su valoración categórica. Así, el $D P D$ cuenta con dos símbolos, la bolaspa $\left({ }^{\otimes}\right)$ y el asterisco $\left(^{*}\right)$, que sirven respectivamente para indicar si una construcción es valorada como incorrecta, en el sentido de no adecuarse al estándar, o si es agramatical, en cuanto a que no se ajusta al sistema estructural de la lengua en un momento determinado. En el siguiente fragmento, en el que se presenta como ilustración de una construcción no ejemplar una cita periodística que incurre en el dequeísmo, llama la atención que el alejamiento del estándar en el caso de las fuentes literarias se identifique con un deseo consciente por parte del escritor de manifestar la variación lingüística en el parlamento de sus personajes frente a lo que ocurre en el discurso periodístico, en el que tal alejamiento se atribuye implícitamente a una inadecuación discursiva no premeditada sino fruto de falta de competencia idiomática:

El símbolo $\left({ }^{\otimes}\right)$ se antepone a las citas y ejemplos que ilustran usos incorrectos o desaconsejados. Es, pues, una marca de «incorrección», entendida esta como inadecuación a la norma culta: ${ }^{{ }}$«El ministro de Salud [...] aseguró de que está controlado el brote de cólera» (NHerald [EE. UU.] 17.2.97). La aparición de este símbolo ante una cita extraída de un texto literario no debe interpretarse, en ningún caso, como censura al autor del texto, pues los escritores de ficción (novelistas y autores teatrales) utilizan los distintos niveles y registros del habla como uno de los modos de caracterización de sus personajes; por tanto, reflejan en sus obras el habla de sus personajes, no la suya propia.

Las citas periodísticas ilustran incorrecciones consideradas características de determinadas zonas geográficas atribuidas a la influencia del contacto de lenguas. Así, en Paraguay el bilingüismo guaraní-español trae como consecuencia sobre el español hablado en esta zona el uso exclusivo de le con referentes tanto animados como inanimados, independientemente de la función sintáctica del pronombre y del género de

tendencia a no incluir un corpus real aparece en El buen uso del español (2013), obra avalada por la RAE y la ASALE, que se limita a dar explicaciones gramaticales ilustradas con ejemplos construidos. En el caso de Las 500 dudas más frecuentes del español (2013) ni siquiera aparecen ejemplos para ilustrar la pauta gramatical. En ambos casos se trata de obras que abordan la vertiente estrictamente normativa y que no hacen censura explícita en sus prólogos a la lengua de los medios de comunicación. 
su antecedente. En este caso, una vez especificado que se trata de un uso oral, se emplea una muestra periodística -precedida de la bolaspa-, que recoge un intercambio comunicativo en forma de discurso referido:

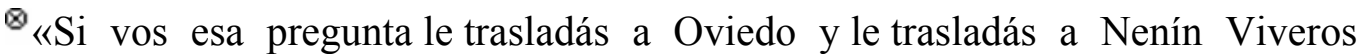
Cartes y te dicen la misma cosa [...], quiere decir que es un verdadero genio, Nicolás» (Abc [Par.] 19.12.96) (DPD 2005. “Leísmo”).

Puede ocurrir que en la ejemplificación de la explicación de un determinado uso idiomático convivan en un mismo fragmento muestras de citas periodísticas precedidas de bolaspa junto a otras consideradas variantes normativas:

Cuando se coordinan dos o más nombres concretos cuyos referentes son entidades distintas, lo normal y recomendable es que cada uno de ellos vaya precedido de su propio determinante: [...] «Se hizo uso ilegal de mi capital y mis acciones bursátiles» (Proceso [Méx.] 9.2.97); y no ${ }^{{ }}$«El diestro y toro se funden en una sola figura» (Clarín [Arg.] 17.3.97); ${ }^{\otimes}$ «Dejé mi cartera y llaves en la silla de la entrada» (Época [Chile] 1.7.96) (DPD “Concordancia”: 2005).

En ocasiones, no se percibe una aplicación sistemática y coherente de la bolaspa en el $D P D$, ya que con cierta frecuencia aparecen expresiones del tipo "no es aceptable en la norma culta", que sustituyen el valor asociado al símbolo en otros casos. Es lo que sucede en el siguiente fragmento, que ilustra un uso no normativo de los pronombres átonos de tercera persona: el loísmo. La incidencia de este fenómeno ha sido siempre muy escasa en la lengua escrita, especialmente en singular, y solo se documenta hoy en textos de marcado carácter dialectal; de ahí que no resulte extraño que la cita periodística que se emplea recoja una interacción dialogal a modo de discurso reproducido:

No son aceptables en la norma culta usos como los ejemplificados a continuación, en los que $l o(s)$ funciona como complemento indirecto: « $\measuredangle T u$ 
identificación?, me dijo; y lo.di mi acta de nacimiento» (Excélsior [Méx.] 8.6.96) (DPD “loísmo") 35 .

Las citas periodísticas ilustran también la amplia casuística de circunstancias (NGLE 2009: 1225-1227) que favorece las construcciones laístas en español, “desaconsejadas” por la Academia a pesar de que persistan en la actualidad en algunos núcleos de Castilla, sobre todo de Burgos, Ávila, Segovia y Valladolid, así como en Cantabria y en Madrid y de que se hayan atestiguado en hablantes cultos: "Después de tres años de seguimiento, no se las detectó ningún tumor (Mundo [Esp.] 8/12/1994). Conviene tener en cuenta que la mayoría de las citas periodísticas que ilustran estas construcciones pertenecen a géneros periodísticos no estrictamente informativos ${ }^{36}$ o se insertan en discursos referidos difundidos a través de los medios de comunicación:

La chica anda esperando desde hace más de medio año las vacaciones en el Caribe que nuestro hombre $\underline{\text { la }}$ prometió en un arrebato de lujuria ( $A B C$ 26/4/1988).

Básicamente la pagan por que se quite la ropa. Es como decir que está vendiendo su cuerpo y haciendo mucho dinero por ello (El Mundo [Esp.] $5 / 10 / 1995)$.

A mi hija la robaron los pendientes, las pulseras y el dinero que llevaba, además de intentar abusar de ella ( $A B C$ 13/11/1987).

Parece muy celosa de su propia intimidad. No se la conoce varón, por ejemplo (Tiempo [Esp.] 9/4/1990).

Aunque, tal y como se ha puesto de manifiesto en los párrafos anteriores, se utilicen muestras reales para ejemplificar variantes no normativas, lo habitual es que la $N G L E$

\footnotetext{
35 Esta misma cita periodística se emplea en la $N G L E$ (16.10n: 1229) dando la siguiente explicación "Puede favorecer la presencia del loísmo, y también del laísmo, la inseguridad en cuanto al régimen de determinados verbos, acompañada del temor a incurrir en leísmo. Sucede, por ejemplo, con verbos que significan transacción, como dar, dejar, prestar, quitar, vender, etc., en los que el complemento de persona, que es indirecto, puede verse expresado mediante los pronombres $l o(s) / l a(s)$, atraídos a esta función desde el directo de cosa, como en [...] y lo di mi acta de nacimiento y este, o sea, y me revisaron mis cosas (Excélsior 8/6/1996).

${ }^{36}$ Se deduce que pertenecen a géneros de opinión por estar muy marcada la subjetividad del emisor.
} 
ilustre tales construcciones a partir de ejemplos construidos por el gramático. No obstante, en el primero de los casos es recurrente el empleo de contextos de interacción $\mathrm{y}$ discurso referido que el periodista acoge e inserta en el suyo declinando responsabilidad enunciativa:

[...], el interrogativo cuál solo se flexiona en número. En algunas variedades del español rural (sobre todo el europeo), se documenta la variante en femenino cuála/cuálas, e incluso el neutro cuálo. Se recomienda evitar todas estas formas en cualquier registro lingüístico porque están muy desprestigiadas. En la lengua escrita solo se registran en ocasiones cuando el autor desea que sus personajes reflejen estas modalidades, como en No sabias a cuála mirar de tantas como habia bailoteando (Berlanga, Gaznápira). Es también raro el relativo cuala, que se ha documentado en esas mismas variedades y se recomienda evitar. En usos irónicos o festivos, se atestigua el grupo indefinido cada cuala: Hemos pasado del "Mama, Chicho me toca...", a que cada cuala se toque los sitios de Zaragoza tirando por la parte de los montes de la Puebla (ABC 16/8/2009) (NGLE 2009: 1559).

La variante regular habemos, que no ha pasado a los registros formales, se encuentra en el habla coloquial de muchos países hispanohablantes, a veces, incluso, entre personas cultas: Habemos maestros que tienen 25 años de enseñanza (Proceso [Méx.] 12/1/1997) (NGLE 2009: 248).

En otras ocasiones la preceptiva académica atribuye al lenguaje periodístico la responsabilidad del incremento de una construcción no normativa fruto de la mayor permeabilidad hacia lo foráneo, como ocurre con la construcción galicista venir de + infinitivo empleada con el valor de acabar de+ infinitivo, uso que considera incorrecto. La crítica es explícita y se vincula no solo a casos de reproducción de discursos ajenos sino a la elaboración discursiva propia del periodista. Ambos casos conviven en la ejemplificación del siguiente fragmento:

Se percibe cierto aumento en el empleo, sobre todo en los medios de comunicación, de la construcción «venir de + infinitivo» empleada con el valor de «acabar de + infinitivo», por calco del francés: Esta actuación ha sido un paso adelante. Y más, teniendo en cuenta que vengo de pasar un bache malo 
(Mundo [Esp.] 15/8/1995), El secretario de Estado para Cultura que viene de ser el portavoz de Cultura [...] (ABC Cultural 31/5/1996); Demichelis, quien viene de ganar la Copa de Alemania el sábado y hoy quedó a un paso de la Bundesliga, espera jugar de local durante el Mundial (Clarín 3/5/2006)" (NGLE 2009: 2167).

Frente a esta censura explícita, en la justificación gramatical de la $N G L E$ hay implícitas y contenidas polifónicamente censuras veladas a lo que se oye en los medios. De este modo, en la explicación gramatical se alude a que un determinado uso "se ha documentado", que "existen testimonios recientes" de él o que "se registran solo ocasionalmente" pero que en ningún caso se recomienda. En el siguiente fragmento se alude al caso de miembra, que recogieron los medios de comunicación a partir de las declaraciones de la ministra Bibiana Aído:

El sustantivo masculino miembro designa cada una de las extremidades articuladas por el tronco del ser humano o de los animales. Se usa como epiceno cuando designa la persona que se integra en un grupo o en una comunidad, pero empieza a ser empleado también como común en cuanto al género en este último sentido: el miembro/la miembro. He aquí algunos ejemplos de este uso, que se considera correcto: "Entre los efectos que le fueron incautados a la miembro de ETA se incluye una agenda electrónica" (Vanguardia [Esp.] 31/8/1994) [...] Así pues, se admiten las dos opciones en alternancias como Ella es \{el $\sim$ la\} miembro más notable del equipo. Se ha documentado el sustantivo miembra, que no se recomienda (NGLE 2009: 121).

Esta censura velada coincide habitualmente con puntos de la gramática que están en ebullición por tratar aspectos vinculados a cambios sociales, tales como los que tienen que ver con la creación de los femeninos en los nombres de cargos o profesiones antes exclusivas de los hombres. Los medios de comunicación suelen ser los primeros en acoger en sus textos este tipo de innovaciones (reguladas por sus libros de estilo) y, por lo tanto, podría pensarse que este tipo de redacción de la $N G L E$ se refiriera a usos frecuentes en ellos no recomendados por la institución:

[...] para designar la mujer que ejerce hoy el sacerdocio en ciertas confesiones cristianas no es normal el sustantivo sacerdotisa, pero empieza a emplearse el 
sustantivo sacerdote (una sacerdote), que pasa de esta forma al grupo de los comunes en cuanto al género, como en La sacerdote pudo perdonar (Mundo [Esp.] 9/3/2006) Existen testimonios recientes de la variante sacerdota, que no se recomienda [...] (2009: 93).

Suelen ser comunes en cuanto al género los sustantivos que designan grados de la escala militar, sea cual sea su terminación: el alférez/la alférez [...] Cabe agregar el soldado/la soldado. Se registran solo ocasionalmente usos de la soldada, opción que no se recomienda. Para aludir a las mujeres que poseen esta profesión es común también las mujeres soldado(s), además de las soldados: 1.072 mujeres soldado solicitaron la baja por depresión en el Ejército en cuatro años (Mundo [Esp.] 11/2/2002) (2009: 105-106).

Sin adoptar una actitud de crítica categórica, la redacción académica puede llegar a proponer redacciones alternativas a las originales, independientemente de que las construcciones modificadas se asocien a ámbitos discursivos específicos:

El uso de la pasiva refleja con complemento agente solo se da, esporádicamente, en el lenguaje jurídico-administrativo: «Los recursos se presentaron por el sector crítico y aún no ha habido respuesta» (Abc [Esp.] 29.1.85); pero incluso en estos casos resulta más natural el empleo de la pasiva perifrástica: Los recursos fueron presentados por el sector crítico (DPD "Se": 2005).

En el lenguaje administrativo, periodístico y burocrático se construyen a menudo grupos nominales con el artículo determinado y el adjetivo mismo (la misma, lo mismo, los mismos, etc.) con el valor anafórico de los demostrativos o los posesivos [...]: El fiscal hizo eso después de leer parcialmente la orden recibida de sus superiores para no pedir medidas cautelares y de decir que estaba conforme con la misma (País [Esp.] 17/7/1997). En estos ejemplos, el mismo se emplea exclusivamente con valor anafórico, sin su significado habitual de identidad e igualdad. [...] En [el ejemplo] de El País se podría cambiar la misma por ella (NGLE 2009: 1206-1207).

De todo lo expuesto anteriormente se deduce que hay una escala de normatividad vinculada a las muestras de publicaciones periódicas que oscila desde la ilustración de la pauta gramatical (lo más habitual) hasta su empleo como variantes incorrectas objeto de censura. En este último caso, lo más frecuente es que se empleen ejemplos que, 
aunque difundidos a través de los medios, no responden a estructuras propias del discurso informativo sino a secuencias de discurso referido más o menos explícitamente marcado en el marco contextual de la cita.

4. Normativa académica y libros de estilo: ¿Relación de convivencia y reciprocidad?

La existencia de un asidero legitimado en la autoridad idiomática en el que poder disipar las incertidumbres lingüísticas convive en la actualidad con los libros de estilo que regulan la producción periodística. En este contexto, cabe plantearse si la relación es siempre de coincidencia y reciprocidad ${ }^{37}$. Tal y como pone de manifiesto Vellón (2013), lo habitual es que los libros de estilo resuman y apliquen la directriz académica. No obstante, en algunos casos se hacen recomendaciones alternativas de uso al considerar que la rígida aplicación de la norma académica mermaría dinamismo, fluidez o claridad al estilo periodístico:

Las normas [gramaticales] que se recogen en este capítulo no son, ni pretenden ser, un tratado de gramática, ni siquiera un resumen articulado. Su propósito es otro: refrescar las reglas gramaticales que con más frecuencia se quebrantan y limitar o precisar el uso de algunas de ellas en beneficio de la redacción periodística (El País, 2008: 145).

Así, en relación a las concordancias referenciales (ante las que la Academia se muestra cada vez más permisiva), los libros de estilo manifiestan explícitamente la necesidad de no aplicar en todos los casos las concordancias gramaticales que, si bien son las recomendadas como más cultas por implicar mayor dominio de la sintaxis, pueden originar expresiones anómalas en casos determinados en los que la realidad se impone a la gramática:

\footnotetext{
${ }^{37}$ Esta coincidencia es patente en el caso de las normas ortográficas: "La edición de 2010 de la Ortografía de la lengua española ha confirmado cambios en la acentuación de algunos términos como el adverbio solo, los demostrativos este, esta, esto, esa, esos, etc., la conjunción o, palabras que han pasado a considerarse monosílabas y aquellas que permiten doble acentuación. La palabra solo. Se evitará la tilde en dicho adverbio y se podrá prescindir de ella incluso en los casos de ambigüedad. Como recurso para evitar la ambigüedad, se puede sustituir dicho adverbio por sus formas sinónimas solamente o únicamente" (Libro del estilo urgente de la Agencia Efe, 2011: 293).
} 
Sujeto y verbo han de mantener preferiblemente concordancia de número. Debe escribirse 'un grupo de personas se reunió ayer' o 'el 60\% de los encuestados opina...', pero no 'un grupo de personas se reunieron ayer' o 'el $60 \%$ de los encuestados opinan...' No obstante, no hay que aplicar esta norma a rajatabla y escribir 'el 5\% de las mujeres está embarazado'. Para casos determinados, se puede modificar la concordancia de género y número (El País, 2007: 149-150).

El deseo de dar legitimidad a una aplicación particular lleva a buscar fuentes autorizadas alternativas a la Academia que respalden la iniciativa lingüística adoptada por el medio. Así, para justificar la combinación a por, censurada anteriormente por la institución pero recogida como normativa en la $N G L E$ (2009: § 29.5n, p. 2250), se esgrime la opinión de Manuel Seco y María Moliner en el Libro de estilo de El País:

La combinación a por, aunque censurada por la Real Academia, puede emplearse. En primer lugar, por lo que Manuel Seco (Diccionario de dudas y dificultades de la lengua española, página 6) llama su 'ventaja expresiva'. No es lo mismo -explica- 'fui por ella', construcción ambigua en cuanto puede significar tanto 'fui a causa de ella' como 'fui a buscarla', que 'fui a por ella', en cuyo caso sólo equivale a 'fui a buscarla'. En segundo lugar, por lo que él y María Moliner (Diccionario de uso del español, página 832) subrayan: que no es el único supuesto en el que se combinan dos preposiciones. Ejemplos: 'por de pronto', 'en contra de lo dicho', 'por entre las nubes', 'desde por la mañana' ( $E l$ País, 2008: 147).

En otros casos, como ocurre con la feminización de los sustantivos que designan profesiones, cargos y títulos, las posibilidades contempladas por la norma académica son restringidas por los libros de estilo aludiendo en muchos casos a la falta de aclimatación social. Así, a pesar de la incorporación de los femeninos por moción al diccionario académico, se sigue recomendando en periódicos de referencia el tratamiento de determinadas profesiones como sustantivos comunes en cuanto al género, independientemente de la línea ideológica del medio:

En la última edición de su diccionario (21. ${ }^{\mathrm{a}}$, 1992), la Real Academia ha recogido (también) en femenino la inmensa mayoría de los cargos, títulos, profesiones desempeñados por mujeres. No obstante, algunos de estos 
femeninos no sólo no están todavía bien asentados en el uso, sino que «suenan» mal a los usuarios, que en ocasiones los rechazan abiertamente. Entre ellos jueza, edila, concejala, bedela y tenienta, que en $A B C$ se mantendrán con género común: (el/la) juez, edil, concejal, bedel, teniente (ABC, 2001: 86).

Cargos y títulos observarán rigurosa concordancia de género con sus poseedores. Así, se escribirá 'la doctora', 'la ingeniera', 'la diputada', 'la jefa' o 'la primera ministra' cuando tales condiciones se refieran a una mujer [...]. El hecho de que se escriban en femenino profesiones que en otro tiempo estuvieron reservadas a los hombres no debe inducir a un uso equivocado del idioma. Así, por ejemplo, no debe escribirse 'jueza', cuando no se usa 'juezo', sino 'juez'. No ocurre igual con 'médica', femenino de 'médico' (El País, 2008: 150).

juez. En femenino permanece invariable (El Periódico de Catalunya 2002: 190).

Finalmente, cabe señalar cómo hay ocasiones en las que la norma académica admite una determinada construcción como correcta haciendo alusión en su formulación a la poca conveniencia de emplearla en los medios de comunicación, según se recoge explícitamente en los libros de estilo, tal y como sucede con el condicional de rumor:

Algunos diarios hispanohablantes han optado por excluir este uso particular del condicional de conjetura en sus libros de estilo. No lo hacen, sin embargo, porque exista incorrección gramatical en dicha construcción, sino porque el rumor no debe ser presentado como noticia (NGLE 2009: 1782).

\section{Conclusiones}

Uno de los objetivos planteados en este estudio era explicar los motivos por los que la ejemplificación periodística ha incrementado su presencia en la reciente producción académica. Es evidente que desde la perspectiva normativa existe un marcado interés práctico por acercarse a los puntos de vacilación reales del idioma. No obstante, consideramos que la incorporación de estas muestras procedentes de la prensa está principalmente motivada por la actual política lingüística de la Academia en relación 
con la codificación de la lengua española, más cercana a las actuales concepciones de la lingüística variacional ${ }^{38}$ :

Al cambiar la concepción centralista de la descripción del modelo de lengua (un centro, anclado geográficamente en la zona septentrional de España, y una periferia, integrada por el español meridional, Canarias y América), cambian también las muestras elaboradas sobre las que se cimienta la codificación gramatical sin perder de vista su labor institucional como garante de la unidad de la lengua que tiende, obviamente, a primar la idea de homogeneidad del español (español culto), por encima de sus diferencia internas (Méndez 2012: 285).

Esta renovación en los planteamientos codificadores es fruto de una concepción menos monolítica de la lengua y se materializa en la inclusión de tipologías textuales que habían quedado al margen de las tradiciones lingüísticas susceptibles de irradiar una norma de carácter ejemplar y carentes de interés estilístico y retórico, entre las que se encontraban los textos periodísticos. En este sentido, la producción normativa académica, representada por el $D P D$ y la $N G L E$, ha aumentado notablemente el número de muestras de prensa utilizadas en la ejemplificación gramatical. Así, de las tres publicaciones recogidas en el Esbozo en 1973 se ha pasado a 316 en la NGLE (2009). A pesar de este notable incremento, no hay -a excepción de los escasos ejemplos contenidos en $D P D$ - una apertura hacia muestras periodísticas procedentes de textos orales. Lo interesante, sin embargo, no es tanto el incremento cuantitativo sino el cambio cualitativo que se aprecia en el tratamiento otorgado a las fuentes periodísticas tanto en lo que se refiere a los géneros más empleados como a la valoración conferida a la cita en la redacción gramatical. En relación al primer aspecto, tanto el $D P D$ como la $N G L E$ acogen muestras que no proceden exclusivamente (aunque sí mayoritariamente) de los géneros informativos (en su mayoría noticias), como ocurría con las primeras manifestaciones en la preceptiva académica, sino que también emplean como

\footnotetext{
38 "Por su carácter de lengua supranacional, hablada en más de veinte países, el español constituye, en realidad, un conjunto de normas diversas, que comparten, no obstante, una amplia base común: la que se manifiesta en la expresión culta de nivel formal, extraordinariamente homogénea en todo el ámbito hispánico, con variaciones mínimas entre las diferentes zonas, casi siempre de tipo fónico y léxico. Es por ello la expresión culta formal la que constituye el español estándar” (DPD: XIV).
} 
ejemplificación artículos y columnas de opinión. Este hecho está estrechamente vinculado a la función de la cita periodística que, a diferencia de lo que ocurría en sus primeras manifestaciones, ya no se emplea exclusivamente para ilustrar un modelo de lengua descrito a partir de una concepción centralista del idioma (en consonancia con lo que ocurría tradicionalmente con la autoridad literaria) sino que también se utiliza como reflejo de usos no ejemplares o circunscritos a determinados ámbitos geográficos. En estos casos las muestras periodísticas se abren a los géneros no estrictamente informativos por ser los de opinión los más susceptibles de acoger usos idiomáticos no ejemplares o de carácter no panhispánico ${ }^{39}$. En cuanto a la valoración normativa de la ejemplificación periodística, la producción académica oscila entre su tratamiento como patrón idiomático hasta su uso como antimodelo normativo, empleo atestiguado a partir de la existencia de una censura más o menos velada en la redacción. Cabe señalar que el uso de las muestras periodísticas como pautas normativas se concentra en aquellas explicaciones que derivan de características vinculadas al discurso informativo: cita de fuentes, tendencia a la condensación y a la precisión, necesidad de contextualización referencial (temporal y espacial), adaptación a nuevas realidades sociales...

\footnotetext{
${ }^{39}$ De ahí que no resulte extraño que en el capítulo que la $N G L E$ dedica a la interjección (capítulo 32) los ejemplos de citas periodísticas estén tomados de géneros de opinión y pongan de manifiesto la variación en el uso de unas expresiones frente a otras en el ámbito hispánico: "Solo digo, ;ojo! ¡Ojo con no respetar las libertades! (Tiempo [Esp.] 26/11/1990); [...] ¡Guambia con el reculón! ¡El oponente arrugaba! (Guambia 24/5/2003)" (2009: 2521). En esta línea de empleo de géneros periodísticos no estrictamente informativos en la ejemplificación, cabe señalar la explicación gramatical del capítulo XXII de la GDLE, referido a los "sistemas pronominales de tratamiento usados en el mundo hispánico" (1999: 1399-1425), donde para explicar la generalización de vos como tratamiento de confianza en el habla bonaerense, tanto en la lengua oral como en la escrita, en la segunda mitad del siglo XX, se recurre a la entrevista de prensa, en la que la sucesión de intervenciones favorece la aparición de las referencias pronominales hacia los interlocutores: "Este uso incluye los registros orales más cuidados, tales como los empleados en cine, radio y televisión; y en el uso en actos oficiales. Lo mismo ocurre en la lengua escrita, en la publicidad; en traducciones de obras de teatro; en traducciones de artículos de revistas donde personas extranjeras formulan declaraciones; en entrevistas periodísticas o literarias; en la reproducción periodística de diálogos que supuestamente habrían mantenido miembros del gobierno [...] A continuación veremos unos pocos ejemplos reveladores de estos usos. Así, en la traducción de un diálogo, aparecido originalmente en el periódico inglés The Suny reproducido por el prestigioso diario porteño La Nación, entre el Príncipe Carlos de Inglaterra y su esposa, se lee:

DIANA: -Vos podés dormir mañana. Podés dormir en cualquier momento. Pero pensá en mí por una vez, sí, pensá en mí.

CARLOS: - Pensaría más en las otras partes involucradas... Vos vas a cuidarte bien, vos lo sabés.

DIANA: - ¿Cómo te atrevés a ser tan presuntuoso? [La Nación, 14-V-1993]" (GDLE 1999: 1407).
} 
Ambos tratamientos (modelo y antimodelo) constituyen al fin y al cabo directrices prácticas para el uso de la lengua en el banco de prueba que conforman los medios de comunicación, regulados también por los libros de estilo, que aplican a la especificidad del discurso informativo las pautas normativas, adaptándolas cuando las necesidades comunicativas lo requieren. Hay, no obstante, un punto de coincidencia clave: la ejemplificación periodística en la producción académica se concentra cuantitativamente en capítulos que abordan aspectos vinculados al género, la concordancia verbal ${ }^{40}$, los cruces entre pasiva reflejas e impersonales ${ }^{41}$, etc., precisamente los aspectos que habitualmente estructuran la sección gramatical de los manuales de estilo ${ }^{42}$. Esta coincidencia no es fortuita sino que da cuenta de los puntos de inestabilidad de nuestro sistema lingüístico actual, vulnerablemente expuestos en la producción periodística.

40 De este modo, las citas periodísticas se concentran para ejemplificar la alternancia -admitida normativamente- en el uso de la concordancia en español del verbo ser cuando sujeto y atributo no presentan coincidencia de número (NGLE 2009: 2809 y 2810): "Para la ciudadana Janet Solís, el problema son las señoritas que se encuentran a la entrada de la oficina (Salvador Hoy 3/7/1997); [...] Su fuerte son los arreglos con flores de papel (Salvador Hoy 2/11/2000) [...] Y no me preocupa el premio ni el castigo, porque el infierno son los otros y nosotros (Vanguardia [Esp.] 24/10/1994); Su principal destino es los países limítrofes (Razón [Esp.] 2/9/2002); Otro problema para la zona son las paredes linderas y la falta de distancia entre una vivienda y otra (País [Ur.] 12/7/2001)".

${ }^{41}$ Constituye uno de los puntos de vacilaciones en el lenguaje periodístico; de ahí que no resulte extraño que tanto el $D P D$ como la $N G L E$ utilicen muestras periodísticas en su ejemplificación: “Algunos verbos transitivos, como nombrar, elegir, seleccionar, contratar y similares, admiten ambas construcciones y pueden dar lugar, sin reparos, a oraciones de pasiva refleja con sujeto de persona determinado; así, tan correcta es la oración de pasiva refleja «Se elegirán los alcaldes por voto popular» (Tiempo [Col.] 2.1.88), donde los alcaldes es el sujeto paciente de se elegirán,como la oración impersonal «Se elegirá a las autoridades de la institución para el período 1997-1998» (Hoy [El Salv.] 23.4.97), que carece de sujeto gramatical y en la que las autoridades es el complemento directo de se elegirá. Suele preferirse, en estos casos, la construcción impersonal, porque al ser imposible su interpretación reflexiva o recíproca no da lugar a enunciados ambiguos. Lo que no debe hacerse es mezclar ambas construcciones: «Se elegirán a los cargos del partido» (Nación [C. Rica] 27.11.96); debió decirse Se elegirán los cargos o Se elegirá a los cargos" (DPD "se": 2005); "Se aconseja evitar los cruces entre pasiva reflejas e impersonales que se producen en las oraciones construidas con complementos definidos de persona introducidos por la preposición $a$ [...] Se encuentran ocasionalmente estas oraciones en los textos clásicos, y a veces en los modernos, unas veces en boca de personajes y otras en el texto que refleja la prosa del autor: [...] Aquí se reciben a varones de 10 a 17 años, que han huido de su casa o que no tienen hogar (Nuevo Día [P. Rico] 6/1/1998); El día de la clausura se premiaron a los mejores jinetes de cada país (Salvador Hoy 19/5/1997)" (NGLE 2009: 3095).

${ }^{42}$ El análisis de Vellón (2013) sobre los principales problemas lingüísticos y de redacción con los que se enfrentan los profesionales de los medios a partir de los contenidos de los libros de estilo recoge, entre otros, apartados referidos a la ortotipografía, la forma de las palabras, las categorías nominales de género $\mathrm{y}$ número, los pronombres y determinantes, el verbo $\mathrm{y}$, finalmente, los adverbios, conjunciones $\mathrm{y}$ preposiciones. 
Bibliografía

ABC (2001): Libro de estilo de Abc. Barcelona: Ariel.

Agencia Efe (2011): Libro del estilo urgente. Madrid: Cátedra.

Alarcos Llorach, Emilio (1994): Gramática de la lengua española. Madrid: Espasa Calpe.

Blas Arroyo, José Luis (2012): “Era Bin Laden un líder de los talibán?...¿o de los talibanes?': presiones externas e internas en un fenómeno reciente de variación morfológica en español”, Revista de Investigación Lingüística, 1,5:3-33.

Borrego Nieto, Julio (2008): "La norma en las gramáticas de la Real Academia Española", $L E A, \mathrm{XXX}, 1,5-36$.

Borreguero Zuloaga Margarita y Álvaro Octavio de Toledo y Huerta (2004): "La organización informativa en los textos periodísticos del siglo XVIII: el Diario Pinciano", Res Diachronicae, 3, 77-106.

Borreguero Zuloaga Margarita y Álvaro Octavio de Toledo y Huerta (2006): "La crónica de sucesos (ss. XVII-XIX). Evolución y desarrollo de la organización informativa textual", en: Jesús Bustos Tovar y José Luis Girón Alconchel (eds.), Actas del VI Congreso Internacional de Historia de la Lengua Española, Madrid: Arco Libros, 2653-2667.

Borreguero Zuloaga Margarita y Álvaro Octavio de Toledo y Huerta (2007): "Presencia y función de los encapsuladores en las crónicas periodísticas del siglo XVII", PhilologiaHispalensis, 21, 125-159.

Bosque, Ignacio/Demonte, Violeta (dir.) (1999): Gramática descriptiva de la lengua española, 3 vols. Madrid: Espasa.

Charaudeau, Patrick (1997): Le discours d' informationmediatique, Paris: Nathan.

Charaudeau, Patrick (2003): El discurso de la información. La construcción del espejo social. Barcelona: Gedisa.

El País (2008): Libro de estilo. Madrid: Ediciones El País.

El Periódico de Catalunya (2002): Libro de estilo. Barcelona: Primera Plana. 
Fries, Dagmar (1989): La Real Academia ante el uso de la lengua (1713-1973). Madrid: SGEL.

Gómez Torrego, Leonardo (1989): Manual de español correcto, Madrid: Arco/Libros.

Gómez Torrego, Leonardo (2004): Nuevo manual de español correcto, Madrid: Arco/libros.

Guillamet, Jaume (2004): "De las gacetas del siglo XVII a la libertad de imprenta del XIX”, en Barrera del Barrio, C. (coord.), Historia del periodismo universal. Barcelona: Ariel. 43-76.

Instituto Cervantes (2013): Las 500 dudas más frecuentes del español, Madrid: Instituto Cervantes.

Kabatek, Johannes (2005): «Tradiciones discursivas y cambio lingüístico». Lexis XXIX, 2, 151-177.

Kabatek, Johannes (2007): «Las tradiciones discursivas entre conservación e innovación». Rivista di Letterature Ispaniche. 10, 331-348.

Koch, Peter y Oesterreicher, Wulf (1990[2007]): Lengua hablada en la Romania: español, francés, italiano, Madrid: Gredos, 2007 [Traducción de Araceli López Serena del original alemán Gesprochene Sprache in der Romania: Französisch, Italienich, Spanisch. Tubinga: Max Niemeyer].

Lázaro Carreter, Fernando (1997): El dardo en la palabra. Barcelona: Galaxia Gutenberg.

Lázaro Carreter, Fernando (2003): El nuevo dardo en la palabra. Madrid: Aguilar.

Mancera Rueda, Ana (2008): “Oralidad y coloquialidad en la prensa española: la columna periodística", en Olza, I; M. Casado; R. González: Actas del XXX-VII Simposio internacional de la SEL. Pamplona: Servicio de publicaciones de la Universidad de Navarra, 469-478.

Mancera Rueda, Ana (2009): Oralización de la prensa española: la columna periodística. Bern: Peter Lang. 
Méndez $G^{\mathrm{a}}$ de Paredes (1998): "Formas de mención implícita en los textos periodísticos: entre el uso y la mención”, en Andalucía como ámbito de interés periodístico. Sevilla: Padilla Libros Editores y Libreros, 141-169.

Méndez Ga de Paredes (1999a): “Análisis de la reproducción del discurso ajeno en los textos periodísticos", Pragmalingüística, 7, 99-128.

Méndez $\mathrm{G}^{\mathrm{a}}$ de Paredes (1999b): "La literalidad de la cita en los textos periodísticos", Revista Española de Lingüística, vol. 30, núm. 1, 147-167.

Méndez $\mathrm{G}^{\mathrm{a}}$ de Paredes (2001a) "Aspectos gramaticales y discursivos de los verbos de comunicación”, en E. Méndez, J. Mendoza y Y. Congostos (eds.), Indagaciones sobre la lengua. Estudios de filología y lingüística española en memoria de E. Alarcos. Sevilla: Universidad de Sevilla, 349-370.

Méndez $\mathrm{G}^{\mathrm{a}}$ de Paredes (2001b) “Análisis de las formas de reproducir el discurso ajeno en los textos periodísticos: el contexto reproductor", en José J. Bustos Tovar et alii. (eds.), 2081-2098.

Méndez Ga de Paredes (2008): "En los comienzos del discurso informativo: los Avisos de José Pellicer de Tovar (1639-1644)", en: Company, Concepción y Moreno de Alba, José. G. (eds.), Actas del VII Congreso Internacional de Historia de la Lengua Española. Madrid: Arco Libros, vol. 2, 1949-1968.

Méndez $G^{a}$ de Paredes (2012): "Los retos de la codificación normativa del español: cómo conciliar los conceptos de español pluricéntrico y español panhispánico”, en Franz Lebsanft, WiltrudMihatsch y Claudia Polzin-Haumann (eds.), El español, ¿desde las variedades a la lengua pluricéntrica? Madrid/ Frankfurt: Iberoamericana/Vervuert, 281-312.

Méndez $\mathrm{G}^{\mathrm{a}}$ de Paredes (2013): “Tensiones entre normatividad lingüística y descripción gramatical en la reciente producción gramatical de la Real Academia Española”, Romanistisches Jahrbuch, 64, págs. 248-285.

Méndez $\mathrm{G}^{\mathrm{a}}$ de Paredes, Elena y Elena Leal Abad (2007a): "La oralidad en el ámbito de los informativos", Oralia (Anejos 3/2), págs. 595- 608. (2007b): "El lenguaje de los informativos entre la oralidad y la escritura(lidad): el telediario del 11-S”, Oralia: análisis del discurso oral, 9 (2007), págs. 185-230. 
Narbona Jiménez, Antonio (2013): “Novedades teóricas en la NGRAE” Orillas, 2.

Pons Rodríguez, Lola y Araceli López Serena (2007): “Un episodio de la morfología histórica del español: la pérdida de la defectividad verbal en los medios, las gramáticas y el uso", en BRAE, tomo 87, cuaderno 295 (enero-junio 2007), 5995.

Pons Rodríguez, Lola y Araceli López Serena (2011): “El lenguaje periodístico como catalizador del cambio lingüístico: la pérdida de la defectividad verbal en agredir", en en Yolanda Congosto Martín y Elena Méndez García de Paredes (eds.), Variación lingüística y contacto de lenguas en el mundo hispánico. In memoriam Manuel Alvar. Madrid/Frankfurt: Iberoamericana/Vervuert, 2011, 545-560.

Real Academia Española (1931): Gramática de la lengua española. Madrid: Espasa Calpe.

Real Academia Española (1933-1936 y 1960-1996): Diccionario histórico del español. lwww.rae.es/recursos/diccionarios [última consulta: 3.3.2014].

Real Academia Española (1973): Esbozo de una nueva gramática de la lengua española. Madrid Espasa Calpe.

Real Academia Española y Asociación de Academias de la Lengua Española (2005): Diccionario panhispánico de dudas, Madrid: Santillana. http://buscon.rae.es/dpdI/.[última consulta: 5.3.2014]

Real Academia Española y Asociación de Academias de la Lengua Española (2009): Nueva gramática de la lengua española. 2 vols. Madrid: Espasa Libros.

Real Academia Española y Asociación de Academias de la Lengua Española (2013): El buen uso del español. Madrid: Espasa Libros.

Vellón Lahoz, Francisco Javier (2013): Norma y estilo en los libros de redacción. Salamanca: Comunicación social.

Recibido: 24 de marzo de 2015

Aceptado: 18 de mayo de 2016

Publicado: 30 de mayo de 2016 